ARNALDO GOLDBAUM

O processo de avaliação do Programa Nacional de Melhoria do Acesso e da Qualidade da Atenção Básica (PMAQ-AB) para saúde bucal no âmbito do Sistema Único de Saúde (SUS)

São Paulo 


\section{ARNALDO GOLDBAUM}

O processo de avaliação do Programa Nacional de Melhoria do Acesso e da Qualidade da Atenção Básica (PMAQ-AB) para saúde bucal no âmbito do Sistema Único de Saúde (SUS)

\section{Versão Corrigida}

Dissertação apresentada à Faculdade de Odontologia da Universidade de São Paulo, para obter o título de Mestre, pelo Programa de Pós-Graduação em Ciências Odontológicas.

Área de Concentração: Odontologia Social Orientador: Prof. Dra. Maria Ercília de Araújo

São Paulo 
Autorizo a reprodução e divulgação total ou parcial deste trabalho, por qualquer meio convencional ou eletrônico, para fins de estudo e pesquisa, desde que citada a fonte.

Goldbaum, Arnaldo.

O processo de avaliação do Programa Nacional de Melhoria do Acesso e da Qualidade da Atenção Básica (PMAQ-AB) para saúde bucal no âmbito do Sistema Único de Saúde (SUS) / Arnaldo Goldbaum; orientador Maria Ercília de Araújo. -São Paulo, 2014.

76 p. : fig. ; $30 \mathrm{~cm}$.

Dissertação (Mestrado) -- Programa de Pós-Graduação em Ciências Odontológicas. Área de Concentração: Odontologia Social. -- Faculdade de Odontologia da Universidade de São Paulo.

Versão Corrigida.

1. Saúde Bucal. 2. Políticas Púbicas - Avaliação. 3. Saúde da Família. 4. Sistema Unificado de Saúde. I. Araújo, Maria Ercília de. II. Título. 
Goldbaum A. O processo de avaliação do Programa Nacional de Melhoria do Acesso e da Qualidade da Atenção Básica (PMAQ-AB) para saúde bucal no âmbito do Sistema Único de Saúde (SUS). Dissertação apresentada à Faculdade de Odontologia da Universidade de São Paulo para obtenção do título de Mestre em Ciências Odontológicas.

Aprovado em: 17/02/2014

\section{Banca Examinadora}

Prof(a). Dr(a). Maria Ercília de Araujo

Instituição: FOUSP Julgamento: Aprovado

Prof(a). Dr(a). Antônio Carlos Frias

Instituição: FOUSP Julgamento: Aprovado

Prof(a). Dr(a). Célia Maria Sivalli Campos

Instituição: EEUSP Julgamento: Aprovado 
Dedico esse trabalho aos meus pais, irmãos e a minha esposa, pelo apoio incondicional, e a Carolina, pela dose diária de alegria. 


\section{AGRADECIMENTOS}

A Prof. Dra. Maria Ercília de Araújo pela orientação, acompanhamento, e todo incentivo proporcionado ao longo da minha formação, que contribuiu na concretização deste trabalho.

O Prof. Dr. Antônio Carlos Frias que me estimulou e acompanhou o desenvolvimento deste trabalho. Também me abriu as portas para aprofundar meus conhecimentos Odontologia em Saúde Coletiva, e na experiência como estagiário da disciplina dos alunos da graduação.

A Prof. Dra. Fernanda Campos de Almeida Carrer, que sempre esteve ao me lado ensinando e me apoiando para a minha formação intelectual. Também agradeço pelo apoio para a realização deste trabalho, e pela oportunidade de estagiar na disciplina de Clinica Ampliada em Promoção de Saúde.

A Dra Maria Eugênia Lemos Fernandes, coordenadora geral da equipe técnica da Associação Saúde da Família, onde trabalho. Obrigado por incentivar realização deste trabalho.

Agradeço todos os meus colegas do Departamento de Odontologia Social, pela amizade, apoio e companheirismo por todos esses anos.

Agradeço e reconheço toda a atenção dispensada pela secretaria do departamento de odontologia social.

A todos meus colegas de trabalho, que sempre tiveram disposição em me ajudar nos momentos mais difíceis desta trajetória, em especial Dra Ana Flávia Pagliusi, Dr Davi Rumel, Dra Rosicler Di Lorenzo, Roseli Zambelli, Ana Honorato, Ivonete Barbosa, Vanilda Silva e Andrea Borella.

Aos meus tios, Moises e Joana, pelo estímulo no caminho da Saúde Pública.

A minha esposa e filha pela compreensão e estímulo. Aos meus irmãos Sérgio e Mauro e meus pais, Henrique e Renata que sempre estiveram ao meu lado.

Ao meu pai, Henrique Goldbaum, um exemplo para mim. 


\section{RESUMO}

Goldbaum A. O processo de avaliação do Programa Nacional de Melhoria do Acesso e da Qualidade da Atenção Básica (PMAQ-AB) para saúde bucal no âmbito do Sistema Único de Saúde (SUS) [dissertação]. São Paulo, Universidade de São Paulo, Faculdade de Odontologia; 2014. Versão Corrigida.

O Programa Nacional de Melhoria do Acesso e da Qualidade da Atenção Básica (PMAQ-AB), criado pela Portaria № 1.654 GM/MS de 19 de julho de 2011, visa promover a ampliação do acesso e a melhoria da qualidade da atenção básica, garantindo um padrão de qualidade comparável a nível nacional, regional e local. Lançado em 2011, o programa contemplou, em seu primeiro ciclo, a adesão de Equipes de Saúde da Família e de Atenção Básica parametrizadas, incluindo equipes de Saúde Bucal. O segundo ciclo se iniciou em 2013 com a novidade da ampliação da adesão das Equipes de Saúde da Família, equipes parametrizada e Equipe de Saúde Bucal, sem limite para a adesão das equipes do município. Outra novidade é a inclusão dos Núcleos de Apoio a Saúde da Família, e Centros de Especialidades Odontológicas. A dissertação teve como objetivo avaliar o potencial de contribuição do processo do Programa Nacional de Melhoria do Acesso e da Qualidade da Atenção Básica para o fortalecimento e consolidação da Política Nacional de Saúde Bucal, no âmbito do Sistema Único de Saúde. Para tanto foi realizada a discussão com base na literatura descritiva, com análise e interpretação de artigos, periódicos, livros, textos institucionais, além de leis e portarias. O estudo permitiu revisar a história das políticas públicas de saúde no Brasil, evidenciando as dificuldades de implementação da saúde bucal antes da criação da Política Nacional de Saúde Bucal, criada no governo do partido do trabalhadores. Por outro lado a participação das equipes de saúde bucal no PMAQ, e mais recentemente a participação dos Centros de Especialidades Odontológicas, parece fortalecer a Saúde Bucal, uma vez que este é o maior processo de avaliação que o Sistema Único de Saúde está sendo submetido.

Palavras-chave: Avaliação de Políticas Públicas, Programa Saúde na Família. 


\begin{abstract}
Goldbaum A. The evaluation Process of the National Program for Improving Access and Quality of Primary Care for oral health within Sistema Único de Saúde, the national health system [dissertation]. São Paulo, Universidade de São Paulo, Faculdade de Odontologia; 2014. Versão Corrigida.
\end{abstract}

The National Programme for Improving Access and Quality of Primary Care, created by Ordinance No. 1654 GM / MS July 19, 2011, aims to promote increased access and improved quality of basic care, ensuring a standard of quality comparable to national, regional and local level. Launched in 2011, the program included in its first cycle , the accession of Family Health and parameterized Primary Care Teams, including oral health teams. The second cycle began in 2013 with the novelty of the expansion of membership of Family Health Teams, parameterized teams, and Dental Health Team , with no limit for membership of the county teams. Another novelty is the inclusion of Family Health Support Centers and Dental Specialty Centers. The dissertation aims to evaluate the potential contribution of the National Program for Improving Access and Quality of Primary Care for the strengthening and consolidation of the National Oral Health Policy within Sistema Único de Saúde (SUS), the national health system. Methodology included discussion based on descriptive literature, analysis and interpretation of articles, journals, books, institutional texts, in addition to laws and ordinances. The study allowed us to review the history of public health policies in Brazil , highlighting the difficulties in implementation of oral health before the creation of the National Oral Health Policy, created by government of Partido dos Trabalhadores. On the other hand the involvement of oral health teams in the National Program for Improving Access and Quality of Primary Care and more recently the participation of Dental Specialty Centers seems to strengthen the National Oral Health Policy, since this is the largest evaluation process that the Health System is being submitted

Keywords: Public Policy Assessment, Family Health Program. 


\section{LISTA DE QUADROS}

Quadro 2.1 - Objetivos da Gestão em Saúde. .32

Quadro 2.2 - Indicadores de Desempenho .46

Quadro 2.3 - Indicadores de monitoramento..... .47

Quadro 2.4 - Indicadores para as Equipes de Saúde Bucal .48

Quadro 2.5 - Instrumento Autoavaliação para Melhoria do Acesso e Qualidade da Atenção Básica .50 


\section{LISTA DE ABREVIATURAS E SIGLAS}

ACS Agente Comunitário de Saúde

AGSS Avaliação para a Gestão de Serviços de Saúde

Al Apoio Institucional

AMAQ-AB Autoavaliação para Melhoria do Acesso e Qualidade da Atenção Básica

AMQ Avaliação para Melhoria da Qualidade

APS Atenção Primária à Saúde

ASB Atenção em saúde Bucal

ASB $\quad$ Auxiliar em Saúde Bucal

BPA Boletim de Produção Ambulatorial

CACONS Centro de Alta Complexidade em Oncologia

CAPS Caixas de Aposentadoria e Pensão

CBES Centro Brasileiro de Estudos de Saúde

CD Cirurgião Dentista

CEO Centros de Especialidades Odontológicas

CIB Comissão Intergestores Bipartite

CLT Consolidação das Leis do trabalho

CNES Cadastro Nacional de Estabelecimentos de Saúde

CNSB Conferência Nacional de Saúde Bucal

CTA Comissão técnica de acompanhamento

EAB Equipe da Atenção Básica

EP Educação Permanente

ESB Equipe de Saúde Bucal

ESF Estratégia saúde da Família

FAS Fundo ao Desenvolvimento Social

IAP Instituto de aposentadoria e Pensões

IDH Índice de desenvolvimento Humano

INAMPS Instituto Nacional da Assistência Médica da Previdência Social

INPS Instituto Nacional de Previdência Social

LRPD Laboratórios Regionais de Prótese Dentária 
MPAS Ministério da Previdência e Assistencial Social

MS Ministério da Saúde

NOB Norma Operacional Básica

OCIP Organizações da Sociedade Civil de Interesse Público

OS Organização social

PAB Piso da Atenção Básica Variável

PACS Programa de Agente Comunitário

PC Procedimentos Coletivos

PCA Tool Primary Care Assessment Tool

PAIS Programa de Ações Integradas da Saúde

PIASS Programa de Interiorização das Ações de Saúde e Saneamento

PMA Produção e Marcadores para Avaliação.

PMAQ-AB Programa Nacional de Melhoria do Acesso e da Qualidade da Atenção Básica

PNAD Pesquisa Nacional por Amostra de Domicílios

PNCCSF Programa Nacional de Controle da Cárie Dental e com uso de Selantes e Flúor

PNSB Política Nacional de Saúde Bucal

PPA Plano de Pronta Ação

PPT Plano Preventivo Terapêutico

PRECAD Programa Nacional de Prevenção da Cárie Dental

PSF Programa Saúde da Família

RAS Rede de Atenção à Saúde

SAI Sistema Integrado Ambulatorial

SB Saúde Bucal

SBC Saúde Bucal Coletiva

SGDAB Programas do Departamento da Atenção Básica

SIAB Sistema de Informação da Atenção Básica

SIASUS Sistema de Informação Ambulatoriais do Sistema Único de Saúde

SINPAS Sistema Nacional de Previdência Social

SMS Secretaria Municipal da Saúde

SUDS Sistema Unificado e Descentralizado de Saúde 
SUS Sistema Único de Saúde

TC Termo de Compromisso

TSB Técnico em Saúde Bucal

UBS Unidade Básica de Saúde

UNACON Unidade de Alta Complexidade em oncologia

USP Universidade de São Paulo 


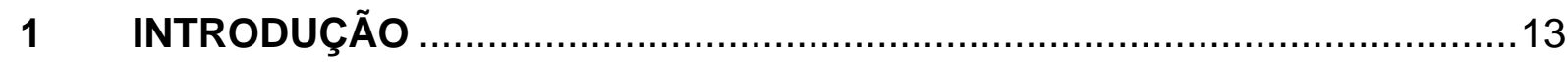

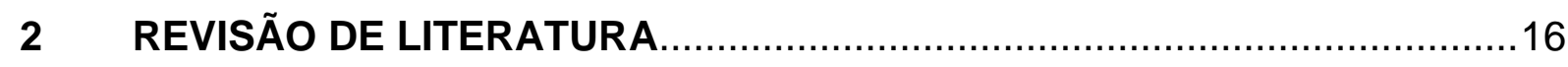

2.1 HISTÓRIA DAS POLÍTICAS PÚBLICAS EM SAÚDE NO BRASIL E O CONTEXTO HISTÓRICO MUNDIAL.........................................................16

2.2 A HISTÓRIA DA SAÚDE BUCAL COLETIVA NO BRASIL ..........................25

2.3 GESTÃo EM SAÚdE: AVALIAÇÃO DE POLÍticAS, PROGRAMAS E

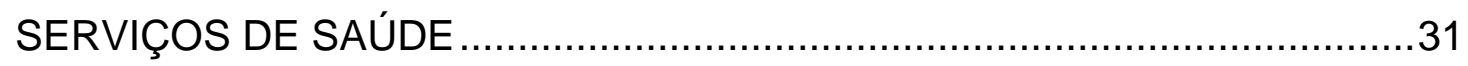

2.4 PROGRAMA NACIONAL DE MELHORIA DE ACESSO E DA QUALIDADE DA

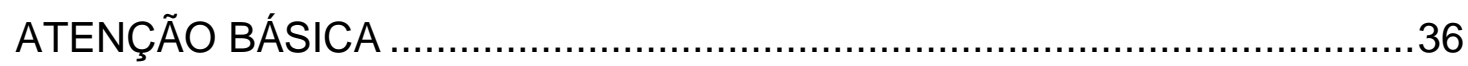

2.4.1 Adesão e Contratualização ..................................................... 40

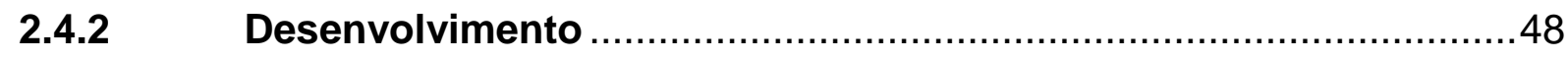

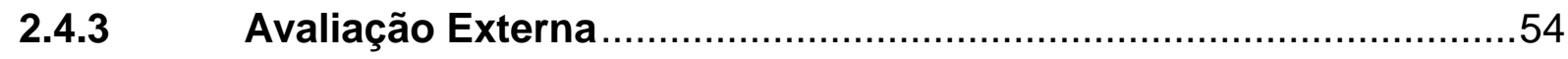

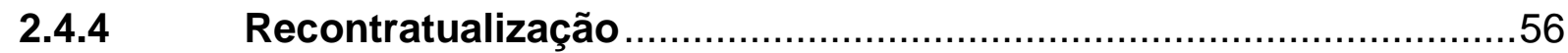

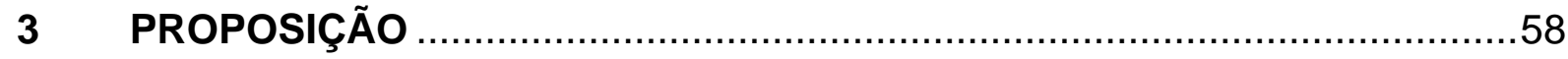

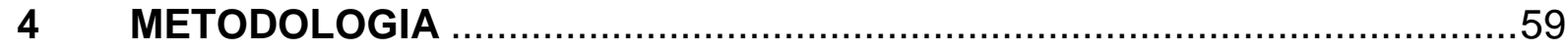

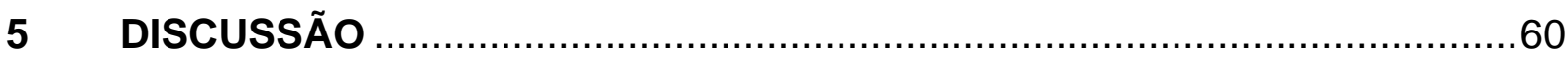

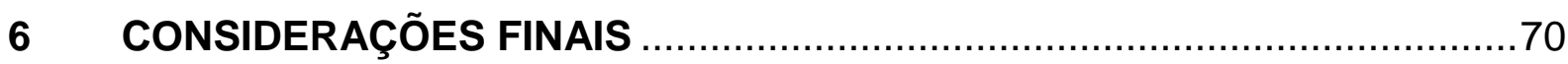

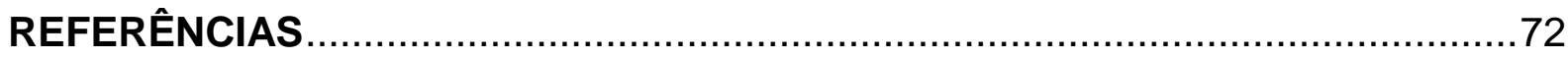




\section{INTRODUÇÃO}

O Programa Nacional de Melhoria do Acesso e da Qualidade da Atenção Básica (PMAQ-AB) é um Programa de indução de novos e inovadores processos que ampliam a capacidade das gestões federal, estaduais e municipais, além das Equipes de Saúde, em ofertarem serviços que assegurem maior acesso e qualidade, de acordo com as necessidades concretas da população. O Programa busca induzir a ampliação do acesso e a melhoria da qualidade dos serviços prestados à população, com garantia de um padrão de qualidade comparável nacional, regional e localmente, de maneira a permitir maior transparência e efetividade das ações governamentais direcionadas à Saúde em todo o Brasil (Brasil, 2011; Brasil, 2012a,b,c,d; Pereira et al., 2012; Reis et al., 2012; Brasil, 2013a,b,c,d; Azevedo et al., 2013; Barros, 2013; Barroso et al., 2013; Pinto, 2012; Pinto et al. 2012; Tanus et al., 2013).

O Brasil está vivendo atualmente mais um importante capítulo da história de suas políticas públicas de saúde, mas sem dúvida o SUS, instituído em 1988, precisou de tempo para que após sua consolidação enfrentasse o desafio de um grande processo de avaliação, tal como é o PMAQ. Uma grande aliada da gestão, que auxilia na melhoria da capacidade de tomada de decisão por parte do gestor é a avaliação, que necessita ser aplicada constantemente durante o processo e que, no caso da saúde enfrenta alguns obstáculos. Os problemas decorrentes de programas, políticas e serviços de saúde, com frequência, exigem uma solução rápida que inviabiliza o processo de avaliação e este é um problema que dificulta a implantação de processos avaliativos em determinadas situações (Tanaka; Tamaki, 2012).

Tanaka e Tamaki (2012), ainda afirmam que os processos de avaliação encontram dificuldade de serem implantados e efetivados no setor da saúde, tendo em vista a própria complexidade do processo saúde doença, e a multicausalidade envolvidas tanto na saúde quanto no adoecimento de uma pessoa ou de uma coletividade e, portanto este é um desafio a ser enfrentado e superado pelo setor "saúde pública" quando da proposta de um processo de avaliação.

Tanaka e Temaki (2012), ao proporem um painel de indicadores para monitoramento e avaliação, afirmam que a gestão necessita construir formas de 
avaliação que permitam compreender melhor as intervenções promovidas pela gestão pública, por intermédio do monitoramento e da avaliação. Os mesmos autores afirmam que a "avaliação baseada na teoria" aparece como promissora tanto para pesquisadores como para os gestores e stakeholders (todas as partes interessadas no processo), desde que articuladas com a compreensão da relevância da "avaliação focada nos resultados". Há, portanto um desafio colocado à gestão pública que se constitui na utilização de estratégias metodológicas que permitam a obtenção de conhecimento sobre as políticas, programas e serviços, por intermédio do monitoramento e da avaliação, partindo da compreensão de que um mesmo programa poderá apresentar diferentes resultados quando implantado sob diferentes condições contextuais, daí o caráter, por vezes subjetivo descrito por Miranda (2005), afirmando "que o propósito primordial da gestão em saúde é a produção de decisões, que desencadeiam o processo de intermediação e implementação das políticas. Há muita complexidade e subjetividade envolvida nesses processos de gestão".

Paim (2005) já evidenciava que diversas iniciativas para a avaliação em saúde no Brasil estavam sendo desenvolvidas de forma progressiva, desde a institucionalização do SUS, e ressaltou que já em 2005 este era um assunto que extrapolava o interesse acadêmico, já que o próprio Ministério da Saúde estava encomendando um conjunto de estudos nessa perspectiva, não só por exigência de financiamento externo, mas devido a uma crescente consciência de responsabilização entre seus técnicos e dirigentes.

A atenção básica foi o primeiro foco do PMAQ, o denominado PMAQ-AB é uma realidade e seu processo encontra-se em fase adiantada de construção e consolidação; entretanto, outros níveis de atenção e outras categorias de serviços têm estruturado seus "PMAQs", é o caso do PMAQ-NASF. As equipes de NASF (Núcleo de saúde da família) foram inseridas no PMAQ com o objetivo de induzir a melhoria da qualidade da atenção destas equipes, fortalecendo-as e aumentando a sua resolutividade, Portarias № 3.124 de 28 de dezembro de 2012 (Brasil, 2012c).

Mais recentemente os Centros de Especialidades Odontológicas (CEOs) também foram incluídos neste processo, já que após cerca de mil unidades instaladas no Brasil e quase dez anos de Brasil Sorridente, julgou-se necessária uma avaliação, nos moldes propostos pelo PMAQ, para a média complexidade em Odontologia. Portaria GM no 261, de 21/02/13 (Brasil, 2013a). 
Tendo em vista o exposto e admitindo que a as políticas públicas de saúde do Brasil estão vivendo atualmente, no Sistema Único de Saúde, um momento singular de avaliação para induzir melhorias e para subsidiar a tomada de decisão da gestão, parece oportuno que sejam realizadas reflexões sobre o tema, especialmente no que tange à Saúde Bucal neste contexto, já que apesar da Política Nacional de Saúde Bucal completar dez anos em 2014, ela ainda não passou por sua maior prova, a alternância de poder no nível federal, já que o mesmo partido governa o Brasil desde 2002, quando da eleição do presidente Luís Inácio Lula da Silva. Acredita-se que o fato da Saúde Bucal se envolver em processos transversais no interior do Ministério da Saúde e promover ações interministeriais, de caráter intersetorais, podem diminuir as fragilidades da própria PNSB, deixando-a mais forte para enfrentar as intempéries que porventura surgirem em seu caminho. 


\section{REVISÃO DE LITERATURA}

Para que se estabeleça o papel do PMAQ-AB na evolução e, porque não afirmar, na consolidação da Política Nacional de Saúde Bucal no âmbito do Sistema Único de Saúde, se faz necessário olhar para passado e reconhecer o impacto que a história das políticas públicas de saúde desempenhou no Brasil, desde a colônia até os dias de hoje. Para tanto esta revisão de literatura será dividida em seções a fim de contar esta história.

As seções são listadas a seguir:

1. História das políticas públicas de saúde no Brasil e o contexto histórico mundial

2. A saúde bucal coletiva no Brasil

3. Gestão em saúde: Avaliação de políticas, programas e serviços de saúde.

4. O Programa Nacional de melhoria do acesso e da qualidade da atenção básica (PMAQ-AB).

2.1 HISTÓRIA DAS POLÍTICAS PÚBLICAS EM SAÚDE NO BRASIL E O CONTEXTO HISTÓRICO MUNDIAL

Antes de abordar a história das políticas públicas no Brasil e sua evolução até os dias de hoje, existe a necessidade de olhar o contexto mundial no qual esta história se desenvolveu, já que alguns fatores marcaram o modo como o homem entendeu a doença ao longo do tempo e devemos estudar esses fatores para que iniciemos nossa reflexão.

O primeiro importante marco histórico foi a Revolução Industrial, com avanço selvagem do capitalismo e consequente deterioração das relações de trabalho. Naquela época as condições de trabalho eram as piores, trabalhava-se muito, ganhava-se pouco, ou quase nada, em locais sem ventilação, sem saneamento e propícios para a disseminação de doenças. Nos ambientes das fábricas agravaram- 
se as epidemias e era evidente a relação entre o adoecimento e o modo como as pessoas trabalhavam e viviam (Paulus Jr; Cardoni Jr, 2006).

Entre 1830 e 1870, vários pesquisadores europeus iniciaram um movimento denominado "medicina social" e uma das figuras mais expressivas dessa época foi Virchow, que em 1847 conseguiu publicar a lei de saúde pública da Prússia, que em última análise dizia que a saúde era um direito de todos e um dever do Estado, além de reforçar a causa social do adoecimento. Virchow afirmava que: "mudam-se as condições da sociedade que acabam as epidemias e transforma-se o perfil das patologias". O movimento iniciava um processo de questionamento de pontos tais como o trabalho infantil e de grávidas, a necessidade por diminuição da carga de trabalho, a importância de se aumentar salários e tempo de descanso, entretanto um achado científico define nosso segundo marco histórico que influenciou na evolução das políticas públicas no Brasil, a descoberta da bactéria, por Pasteur em 1896 (Verdi et al., 2012).

Na história da humanidade, a medicina criou teorias para explicar o contágio entre indivíduos, já se sabia que cheiros de podre, corpos em decomposição, detritos e lixo poderiam trazer doenças, havia a teoria que "miasmas" ou partículas invisíveis tinham a capacidade de invadirem o corpo e o fazer adoecer (Araújo et al. 2007, p. 8). Entretanto a descoberta de Pasteur foi tão grandiosa e atendeu tanto aos interesses dos poderosos e do capitalismo, que as discussões sobre a determinação social da doença ficaram esquecidas. O final do século XIX e o início do século XX foram marcados pela teoria unicausal da doença, em que apenas o aspecto biológico do adoecimento era levado em (Araújo et al., 2007, p. 8; Verdi et al., 2012).

Outro marco histórico que influenciou sobremaneira, os modos como a medicina e as outras áreas da saúde se desenvolveram no Brasil, foi o modelo norteamericano. Isso ocorreu mais recentemente em nossa história, se compararmos com a influência europeia, mas o modelo de ensino de medicina, centrado no biologissismo, na unicausalidade das doenças, excessivamente hospitalocêntrico e fragmentado chegou até o Brasil através da forte influência e do poder econômico da Rockfeller Foundation, retrato do poder capitalista sobre a saúde nos Estados Unidos e alguns autores afirmam que isso causou sérios danos no modo fragmentado, excessivamente especializado e unicausal na saúde pública do Brasil até os dias de hoje (Verdi et al., 2012). 
Uma das preocupações iniciais do Estado Brasileiro, em relação às políticas públicas de saúde, foi o saneamento dos portos, espaços de grande circulação de mercadorias, principalmente os portos de Santos e Rio de Janeiro (Pereira, 2003). Até a década de 1930 as ações de saúde estavam limitadas ao saneamento e controle das endemias (Paulus Jr; Cardoni Jr, 2006). No mesmo período começa a surgir o desenvolvimento do chamado sanitarismo campanhista notadamente até os anos 40 (Paulus Jr; Cardoni Jr, 2006). Havia um claro objetivo de se conter epidemias tais como a febre amarela, peste, cólera, varíola, visando apoiar apolítico agropecuário da época garantido à saúde do trabalhador através de ações de campanhas, que caminhou para o desenvolvimento das ações pelo Estado à população, principalmente após a segunda guerra. (Paulus Jr; Cardoni Jr, 2006).

As ações assistenciais surgem com a Previdência Social, em 1923, após o decreto legislativo conhecido como a Lei Eloy Chaves, com a criação das caixas de aposentadorias e pensão (CAPS). Organizadas pelas empresas, e financiados e administradas pelos empresários e trabalhadores, ofereciam assistência médicas, medicamentos, aposentaria e pensões, em caso de acidentes, para alguns empregados específicos, geralmente empresas estratégicas (Pereira, 2003; Paulus Jr; Cardoni Jr, 2006). Entre 1923 e 1930 surgiram mais de 40 CAPS cobrindo mais de 140 mil beneficiários (Pereira 2003).

A partir de 1933 surgiram os Institutos de Aposentadorias e Pensões (IAP), entidades de grande porte que garantiam a assistência médica e aposentadorias para os grupos de trabalhadores do mesmo ramo de atividade (Pereira 2003; Paulus Jr; Cardoni Jr, 2006). Foram fundados os Institutos dos marítimos, bancários, industriários, entre outros (Pereira, 2003). Os benefícios só eram concedidos aos grupos e indivíduos que contribuíam para a previdência privadas com vínculo trabalhista, portanto, os trabalhadores que possuem carteira assinada (Paulus Jr; Cardoni Jr, 2006).

Em 1953, sob influência do plano SALTE (saúde, transporte, alimentação e energia), formulado pelo governo do General Eurico Gaspar Dutra, surge o Ministério da Saúde (MS), focando as ações no coletivo, campanha e vigilância sanitária. Paralelamente as instituições previdenciárias crescem percebendo as necessidades de garantia da manutenção da força do trabalho cada vez mais urbana e fabril (Pereira, 2003; Paulus Jr; Cardoni Jr, 2006). As várias instituições previdenciárias motivaram, em 1960, a promulgação da lei orgânica da previdência Social (Paulus Jr; 
Cardoni Jr, 2006). Os deveres passaram a ser semelhantes e orientados pela lei, facilitando a fusão das IAPS (Pereira 2003; Paulus Jr; Cardoni Jr, 2006), que evoluíram, 1966, para a criação do Instituto Nacional da Previdência Social (INPS). O INPS consolida o componente assistencial, com marcada opção de compra de serviços assistenciais do setor privado, concretizando o modelo assistencial hospitalocêntrico, curativista e médico centrado (Paulus Jr; Cardoni Jr, 2006).

Em 1974, com a criação do órgão do Ministério da Previdência e Assistencial Social (MPAS), a assistência coletiva e programas incorporam a assistência individual. A assistência médica passou a ser privilegiada priorizando o setor privado e estimulando o desenvolvimento das atividades hospitalares (Paulus Jr; Cardoni Jr, 2006). Com a política de aceleração industrial, desencadeado pelo Presidente Juscelino Kubitscheck de Oliveira, aumenta a demanda para ser atendida pelo sistema de saúde, levando a necessidade de aumentar a capacidade produtiva do serviço de saúde (Pereira, 2003; Paulus Jr; Cardoni Jr, 2006).

Em 1976 nasceu a primeira mobilização social com a formação de Centro Brasileiro de Estudos de Saúde (CBES), movimento critico, político e intelectual, ao sistema de saúde vigente. O movimento nasceu nos Departamento de Medicina Preventiva e no Curso de Saúde Pública da Universidade de são Paulo (USP). Como resultado formou-se o Movimento da Reforma Sanitária no Brasil, que preconizava um modelo de atenção primária da saúde, e foi um grande indutor mais tarde da VIII Conferência da Saúde (Paulus Jr; Cardoni Jr, 2006).

Em 1974 surge o Fundo ao Desenvolvimento Social (FAS) que emprestava dinheiro dos recursos públicos, a juros subsidiados, para construção de hospitais privados, e garantindo o retorno ao Estado através do credenciamento junto ao INPS. No mesmo ano surge o Plano de Pronta Ação (PPA), que facilitou a entrada dos serviços de urgência, e permitiu o atendimento ambulatorial. Foi o início da universalização dos serviços de saúde (Paulus Jr; Cardoni Jr, 2006).

Em 1975 com a lei 6.229/75 que regulamentou o Sistema Nacional de Saúde, ocorreu a primeira tentativa da municipalização da saúde, em que seu artigo continha as competências dos municípios: a manutenção dos serviços de saúde, em especial os de pronto socorro; manter a vigilância epidemiológica; articular os planos locais de saúde com estaduais e federais; Integrar seus serviços no sistema nacional de saúde. Os municípios investiram os recursos em atendimentos especializados e de urgência, dando pouca importância nos atendimentos primários (Paulus Jr; Cardoni Jr, 2006). 
Em 1976, surgia o Programa de Interiorização das Ações de Saúde e Saneamento (PIASS), que visava levar para as comunidades carentes uma nova concepção de saúde, com ações de atenção primária envolvendo a comunidade local (Paulus Jr; Cardoni Jr, 2006), de interesse estratégico para economia, como os produtores de borracha na Amazônia (Pereira, 2003).

Em 1977 o governo criou a SINPAS - Sistema Nacional de Previdência e Assistência Social, Lei 6.439/77e, dentro dela o Instituto Nacional da Assistência Médica da Previdência Social (INAMPS), que passava a ser o grande órgão prestador da assistência médica (Pereira, 2003; Paulus Jr; Cardoni Jr, 2006). Se por um lado o Sistema Nacional de Saúde desenvolvia as ações de saúde de forma fragmentada e sem integração, onde as ações de saúde coletiva era um direito de todos, e a assistência médica individualizada era oferecida apenas aos trabalhadores que contribuíam ao Sistema Nacional de Previdência Social, o SINPAS reforçava a política no modelo médico-assistencial utilizando os recursos da previdência nos contratos das prestações de serviços do setor privado, e multinacionais fabricantes de medicamentos (Pereira, 2003; Paulus Jr; Cardoni Jr, 2006).

No mesmo ano, apesar do Ministério da Saúde reconhecer o papel da esfera municipal na organização dos serviços básicos, na lógica de organização da atenção primária, foi no primeiro encontro municipal do setor de saúde, 1978, que foi concluído que a atenção primária a saúde seria prioridade dos municípios, deixando os casos de maior complexidade para União e Estados (Paulus Jr; Cardoni Jr, 2006).

Em 1982, surgia o Plano de Reorientação da Assistência à Saúde no Âmbito da Previdência Social, visando à racionalização das contas com os gastos hospitalares, abolindo a modalidade do pagamento por unidade de serviço, e valorizando a utilização da capacidade instalada nos serviços ambulatoriais públicos. Seguindo a mesma linha, em 1982 foi formado o convênio trilateral, Ministério da Previdência Social, Saúde e Secretaria do Estado da Saúde, visando a melhor utilização da rede pública de serviços básicos (Paulus Jr; Cardoni Jr, 2006). Posteriormente, a tríade foi substituída pelo Programa de Ações Integradas da Saúde (PAIS), que objetivou a universalização da acessibilidade aos serviços de saúde (Paulus Jr; Cardoni Jr, 2006). As PAIS incorporaram os serviços municipais e estaduais à rede dos serviços pagos para INAMPS, integrando as esferas do governo em comissões interinstitucionais da saúde (Paulus Jr; Cardoni Jr, 2006). Foi um marco na instituição da gestão colegiada nas diversas esferas do governo, responsabilizando 
o município como a porta de entrada do sistema de saúde, as PAIS representaram um estimulo a municipalização (Paulus Jr; Cardoni Jr, 2006).

A VIII Conferência Nacional de Saúde, 1986, propôs o direito universal à saúde, acesso igualitário, descentralização acelerada, e ampla participação popular. A Conferência já apontava para a municipalização, e produziu um relatório que subsidiou os assuntos de saúde na Constituição Federal de 1988 (Pereira, 2003; Paulus Jr; Cardoni Jr, 2006).

Em 1987 foi criado o Sistema Unificado e Descentralizado de Saúde (SUDS), que tinham como principais diretrizes: universalização, equidade no acesso aos serviços de saúde, integralidade do cuidado assistencial, descentralização das ações de saúde e implementação dos distritos sanitários (Pereira, 2003; Paulus Jr; Cardoni Jr, 2006). Pela primeira vez o Governo Federal começou a repassar os recursos para os estados e municípios ampliarem as suas redes de serviços, aproveitando o máximo da capacidade instalada (Pereira, 2003; Paulus Jr; Cardoni Jr, 2006).

A Constituição Federal foi aprovada em 1988 e ficou conhecida como "A Constituição Cidadã", nela a saúde passou a ser de acesso universal e dever constitucional de todas as esferas do governo. O conceito de saúde foi ampliado e vinculado às políticas públicas sociais e econômicas, e de forma integral (Pereira, 2003; Paulus Jr; Cardoni Jr, 2006).

Em 1988, foi aprovada a "Constituição Cidadã", que estabelece a saúde como "Direito de todos e dever do Estado" e apresenta, na sua Seção II, como pontos básicos: "as necessidades individuais e coletivas são consideradas de interesse público e o atendimento um dever do Estado; a assistência médico-sanitária integral passa a ter caráter universal e destina-se a assegurar a todos o acesso aos serviços; estes serviços devem ser hierarquizados segundo parâmetros técnicos e a sua gestão deve ser descentralizada." Estabelece, ainda, que o custeio do Sistema deverá ser essencialmente de recursos governamentais da União, estados e municípios, e as ações governamentais submetidas a órgãos colegiados oficiais, os Conselhos de Saúde, com representação paritária entre usuários e prestadores de serviços (Brasil, 2007).

As leis $8.080 / 90$ de 19 de setembro e a $8142 / 90$ se destacam para o novo modelo. A 8.08/90 sedimenta as orientações constitucionais do Sistema único de saúde, SUS (Paulus Jr; Cardoni Jr, 2006), e estabelece que (Brasil, 2006): 
...a saúde é direito de todos e dever do Estado...." e que as ações e serviços públicos de saúde integram uma rede regionalizada e hierarquizada e constituem um Sistema Único organizado com as seguintes diretrizes: descentralização, atenção integral, com prioridade para as ações preventivas, sem prejuízo para as ações assistenciais e participação da comunidade.

O artigo 199 da lei, também cita que: quando a assistência do setor público não for suficiente para cobertura da população, o setor privado pode somar com participação do sistema em caráter complementar.

A 8142/90 trata da participação popular nas questões de saúde, criando as conferências e os conselhos de saúde em cada esfera do governo como instancia colegiada, orientadoras e deliberativas. As conferências ocorrem de quatro em quatro anos com a participação de vários segmentos sociais, onde são definidas as diretrizes para a formulação da política de saúde nas esferas de governo. Também defini os repasses financeiros diretamente aos Fundos Estaduais e Municipais (Paulus Jr; Cardoni Jr, 2006).

Em relação aos aspectos financeiros, as Normas Operacionais Básicas (NOB), editadas pelo Ministério da Saúde, em 1991, 1993 e 1996 também se destacam na orientação do setor público para a efetiva implantação do SUS (Paulus Jr; Cardoni Jr, 2006; Programa de Saúde da Família Saúde Bucal, 2006). A NOB 1996 definiu a modalidade denominada Gestão Semiplena, onde os municípios tem a possibilidade de autonomia administrativa para a gestão dos recursos financeiros repassados pela União, resultando em maior capacidade de planejamento nos municípios (Pereira 2003; Paulus Jr; Cardoni Jr, 2006).A NOB 1996 também definiu programas para reorientação do modelo da atenção básica, recomendando o Programa de Agente Comunitário (PACS) e o Programa Saúde da Família (PSF), que estabelece incentivo financeiro a ser acrescido no Piso da Atenção Básica (PAB) à medida que estes programas ampliarem a cobertura de serviços.

O PSF é uma estratégia para reorganização da AB do modelo tradicional. Têm como enfoque as ações de promoção da saúde, prevenção dos agravos e recuperação da população com enfoque das famílias, observadas em seu contesto sócio econômico e cultural.

A Equipe de Saúde Bucal só compôs com as Equipes Saúde da Família, na lógica a atenção integral do indivíduo e da família, com a regulamentação da portaria 
144/GM/MS, 28 de dezembro de 2000, e determinou a inclusão da Saúde Bucal (SB), com o intuito de ampliar o acesso às ações de saúde no conjunto das atividades desenvolvidas pela ESF. Foi publicada a portaria $n^{\circ} 267 / 2001$, que dispõe sobre as normas e diretrizes do Plano de reorganização das ações em SB na Atenção Primária (Pereira 2003; Munkeviz, Pelicione, 2010).

Com a implantação do SUS, um gigantesco passo a saúde foi dado disponibilizando o acesso universal, gratuito e de qualidade para toda a população. No entanto, com o passar dos anos, a administração pública direta mostrou-se incapaz de acompanhar as mudanças da nova política, resultando em limitação dos serviços, servidores sobrecarregados, sem perspectivas de crescimento profissional e uma população insatisfeita com o atendimento (Brasil, 2006).

Alcântara, 2011 cita dois novos modelos de gestão da saúde com maior eficiência e eficácia no gerenciamento dos serviços, um da administração pública indireta, como é o caso da fundação estatal, e outro do setor privado, representada pelas organizações Sociais (OS).

O modelo da administração pública indireta é a proposta do Ministério da Saúde que apresentou ao Congresso nacional projeto de lei Complementar 92/2007, visando regulamentar o inciso XIX do artigo 37 da Constituição Federal autorizando a criação de fundações de direito público ou privado em áreas como a saúde, assistência social entre outras; na saúde mais conhecida como fundações estatais (Alcântara, 2011).

A FUNDAÇÃO ESTATAL é um organismo da Administração Pública com flexibilidade e autonomia mais amplas do que as atuais autarquias e fundações públicas de direito público possuem. Poderá dispor de instrumentos administrativos de natureza privada e, nesse sentido, é comparável a uma empresa pública estatal (Brasil 2006).

O projeto das fundações teve o apoio do ministro da saúde do Brasil, José Gomes Temporão, usando na defesa das fundações estatais termos gerenciais como: autonomia, contratos de desempenho, modelos mais eficientes de gestão, cobrança de resultados e remuneração por bom desempenho Em alguns estados federados, como Pernambuco, Rio de janeiro e Sergipe, já foi aprovada a legislação acerca do tema (Alcântara, 2011).

A fundação estatal pode trazer alguns benefícios na gestão pública, em especial no gerenciamento de hospitais de grande porte. Garante maior autonomia e agilidade para as organizações pública, permitindo a contratação via Consolidação 
das Leis do Trabalho (CLT), e não por meio do estatuto do setor público, mantendo o procedimento licitatório para a aquisição de bens e serviços pelas fundações estatais (Alcântara, 2011).

Regulamentada pela Lei Federal 9637/1998, as Organizações Sociais têm sido bastante utilizadas nos serviços de saúde, são entidades privadas sem fins lucrativos, do chamado terceiro setor, contratados pelos governos Estaduais ou Municipais para administração dos hospitais públicos e outros serviços de saúde. Trazem agilidade, eficiência e maior mobilidade da iniciativa privada para gestão de instituições públicas; mais adequada à prestação de serviços da área de saúde que exige prontidão e soluções rápidas (Brasil, 2006 e Alcântara, 2011).

Atualmente o cenário de parceria institucional entre as entidades qualificadas como OSS e a SMS se caracteriza por grande diversidade de contratos que participam de forma complementar e integrada da rede pública de saúde, no âmbito da Atenção Básica, Especializada, Atenção Hospitalar e Serviços de Diagnóstico por Imagem (Brasil, 2006).

O controle é realizado pela Secretária Municipal da Saúde, onde as OSs devem cumprir metas e prazos estabelecidos pelos contratos, e apresentar mensalmente relatórios dos seus indicadores de produção, cobertura da população e qualidade dos serviços prestados, não recebendo o repasse integral caso não cumpram. Uma Comissão Técnica de Acompanhamento (CTA) avalia mensalmente a execução dos contratos, e a valoração trimestralmente. Também passam pela Comissão de Avaliação do Contrato de Gestão e pela Comissão de Acompanhamento do poder Executivo, da câmara Municipal e da Sociedade Civil.

No mesmo raciocínio, em 1999 foi promulgada a lei que regulamenta Organizações da Sociedade Civil de Interesse Público (OSCIP). Seguem os mesmos requisitos que as OSs necessitam para a qualificação, a diferença é que as OCIPs solicitam a habilitação ao Ministério da Justiça. A relação com o poder público se dá mediante Termo de Parcerias (Brasil, lei 9.790, 199) (Azevedo, 2010). 


\subsection{A HISTÓRIA DA SAÚDE BUCAL COLETIVA NO BRASIL}

A saúde não deveria ser dissociada, fragmentada ou compartimentalizada, entretanto ela pode ser compreendida em várias dimensões, que devem ser preservadas, cuidadas e que quando trabalhadas respeitando suas peculiaridades, sem dissociá-las do todo, podem facilitar a formulação de políticas públicas e ações específicas, este é o caso da saúde mental, saúde da mulher, da saúde do homem ou da saúde bucal.

A deterioração da boca e seus componentes geram repercussões na vida e em sua qualidade e no cotidiano do indivíduo, que passam pelo constrangimento, dor, perda de autoestima e dificuldade em ações tais como a fala, mastigação e deglutição, além de repercussões no campo da sexualidade e da erotização. Botazzo em 2000 formulou uma teoria, chamada bucalidade que descreve de forma decisiva as funções da boca e as repercussões bio-psico-sociais que as doenças da boca podem causar.

As doenças da boca implicam em limitações ao trabalho, ao rendimento escolar, à vida em sociedade e com a família. A perda de dentes pode ocasionar em grande dificuldade na mastigação, que gera constrangimentos ao indivíduo de comer em público ou com a família por exemplo. A doença periodontal, por sua vez, e seus odores, podem comprometer a vida amorosa de um indivíduo ou suas relações de trabalho, há evidências que ela pode ocasionar o nascimento de crianças pré-matura e de baixo peso, ou ainda ocasionar uma bacteriêmia em paciente valvares e com outras cardiopatias. O câncer, doença mais grave que pode atingir a boca, repercute de forma intensa e decisiva na vida do indivíduo, já que normalmente seu tratamento é mutilador, gera deformidades intra e extra-orais, que tornam muito difíceis, senão impossíveis, tarefas como comer por boca, falar, deglutir ou até mesmo sorrir. Podese aqui discorrer sobre diversas patologias que afetam a boca e repercutem na vida do indivíduo, entretanto o que se pretende com este texto é enfatizar as diversas dimensões (bio-psico-social) do processo de adoecimento da boca, lembrando aqui, portanto, que ações de manejo dessas doenças devem ser pensadas do ponto de vista do conceito ampliado de saúde e que pensar saúde bucal na lógica do tratamento individual e unicausal é um erro que perdurou por décadas no sistema público e privado brasileiro e que começou a ser corrigido nos últimos anos (Botazzo, 2000) 
Narvai e Frazão (2009a,b) afirmam que a Constituição de 1988 foi um marco para saúde bucal, já que esta foi considerada inseparável da saúde, sendo um direito de todos e um dever do Estado, entretanto os anos que sucederam a promulgação da carta magna não privilegiaram a saúde bucal, nem tão pouco alinharam as políticas de saúde pública odontológicas às diretrizes do recém-criado SUS.

A Saúde Bucal Coletiva (SBC), segundo Narvai e Frazão (2009a,b) é uma área do conhecimento que se dedica a advogar a favor da saúde bucal das populações, que não poderá ser alcançada apenas pela prática odontológica tradicional, mas resultarão da construção social incluindo profissionais de saúde e os cirurgiões dentistas. Esses autores afirmam ainda que a SBC deve romper epistemologicamente com o conceito e práticas da odontologia de mercado hegemônica, marcadamente biologicista, com práticas individuais, doença-centradas e desconsiderando em sua prática a complexidade do processo saúde doença. Em resumo, a SBC deve fomentar a discussão e lutar por uma Odontologia que seja praticada em razão da necessidade de todos e não de uma elite, detentora dos recursos odontológicos sempre caros. A luta da SBC é para que todos tenham acesso a todos os recursos disponíveis para que se garanta saúde bucal de todos e não só dessa elite dominante. A SBC deve lutar por Odontologia Universal, que atenda todos de forma integral, praticando a saúde bucal como parte integrante e inseparável da saúde e fornecendo todos os recursos disponíveis para resolver a demanda de saúde bucal do indivíduo e da coletividade e deve pensar de modo a ofertar mais para quem mais necessita, ou seja de forma equânime (Narvai; Frazão, 2009a,b).

A $1^{\text {a }}$ Conferência Nacional de Saúde Bucal é um exemplo de como o referencial teórico e agenda de discussão da SBC se desenvolveu na história da SBC no Brasil. Em 1986 a 1르 CNSB aprovou deliberações que pontuavam claramente os rumos que a Odontologia deveria seguir para atingir os objetivos da $7^{\mathrm{a}}$ e da $8^{\mathrm{a}}$ conferências nacionais de saúde, definindo que a inserção da saúde bucal no sistema público de saúde deveria ser planejada respeitando as diretrizes de descentralização (estabelecendo competências em cada nível de governo), e que este modelo deveria ser universal, integral, equânime, e com a municipalização dos serviços (Narvai; Frazão, 2009a,b).

Apesar do alinhamento entre o que a SBC pensava e pregava sobre a saúde bucal para os brasileiros, e apesar da constituição declarar que o SUS seria firmado em diretrizes tais como a integralidade e que a saúde bucal não poderia ser dissociada 
da saúde, a história das políticas e ações em saúde bucal após a promulgação da constituição em 1988 e da lei 8080 de 1990 demonstram a dissociação entre os princípios doutrinários do SUS. O programa nacional de controle da cárie dental e com uso de selantes e flúor (PNCCSF) e o PRECAD (Programa Nacional de Prevenção da Cárie Dental), lançados pelo INAMPS e instintos pelo governo Collor dois anos depois, foram baseados na verticalização das ações, de forma centralizadora e autoritária, sendo absolutamente opostos ao que rezava a Constituição (Narvai; Frazão, 2009a,b).

Fernando Collor definiu sua própria política nacional de saúde, chamando-a de plano quinquenal de saúde (1990-95), entretanto neste plano não havia qualquer menção explícita à saúde bucal. Naquela ocasião a coordenação nacional de saúde bucal foi relegada a uma divisão técnica sem poder decisório algum. Nos primeiros anos do SUS, um importante marco para SBC foi a inclusão dos procedimentos coletivos (bochechos fluorados e escovação supervisionada) no sistema de informação ambulatoriais do SUS (SIASUS), com consequente repasse de verba federal para os municípios, pois isso fez com que houvesse espaço para um movimento de valorização das ações de promoção e prevenção e de questionamento do modelo incremental, que no Brasil se tornou sinônimo de "dentista na escola", modelo que excluía boa parte da população, trabalhava na lógica do atendimento individual, curativo e que tinha como premissa que o acúmulo de necessidades da população escolar era inevitável. Este modelo não se alinhava ao conceito de universalidade que doutrina a existência e funcionamento do SUS e alguns autores afirmam que apesar da inoperância parcial das ações em saúde bucal no período pósSUS o desmonte gradual do programa incremental e a realocação de equipamentos odontológicos e dos recursos humanos da escola para unidades de saúde foi um importante evento que possibilitaria mais tarde os avanços de programas posteriores (Narvai; Frazão, 2009a,b).

Após o impeachment do Collor e já no governo Itamar Franco, a saúde bucal continuava sem nenhuma possibilidade de ação junto à política nacional de saúde, entretanto neste período foi realizada a $2^{\text {a }}$ Conferência Nacional de Saúde Bucal, na qual a saúde bucal foi associada ao conceito de cidadania, entretanto as duas conferências não repercutiram de forma decisiva nas políticas de saúde bucal. No governo Fernando Henrique Cardoso não houve avanços significativos para SB, entretanto o piso da atenção básica, que fixou repasses mensais aos municípios 
independente da produção, aumentou a capacidade de resposta local e possibilitou a formulação de políticas e propostas nas diversas áreas, dentre as quais a saúde bucal. Outro marco importante para a SBC e para o SUS foi a inclusão das Equipes de Saúde Bucal no Programa de Saúde da Família em 2000, criado em 1994 pelo então presidente Itamar Franco, ele foi idealizado para ter um equipe mínima composta de médico, enfermeiro, auxiliar de enfermagem e agentes comunitários de saúde. $\mathrm{O}$ incentivo aos municípios para inclusão de cirurgião-dentista, auxiliar e técnico, foi um marco importante para odontologia no serviço público e trouxe à tona discussões importantes como o trabalho em equipe, as ações de saúde bucal coletivas, a multicausalidade do adoecimento do boca, entretanto a expansão da SB no PSF foi tímida, pois não havia uma PNSB clara para suportar a Odontologia no PSF.

O Brasil viveu na instalação e nos primeiros anos do SUS a realidade do neoliberalismo e sua teoria do estado mínimo e os obstáculos que a Odontologia, especialmente a Saúde Bucal Coletiva, enfrentou para se estabelecer e expandir seu alcance, dando voz aos ideias por ela proclamados e estabelecidos, dentre outros movimentos, pelas $1^{\underline{a}}$ e $2^{\underline{a}}$ CNSB, podem ser explicados por razoes políticas e ideológicas.

Em 2002, no entanto, o Brasil elege Luiz Inácio Lula da Silva, um presidente com origem popular, ex-metalúrgico, figura importante na redemocratização do país e que sempre se opôs ao modelo neoliberal. Neste novo contexto político, é que se deu a 3aㅡ Conferência de Saúde Bucal e nela definidos o que seria em 2004 o documento de diretrizes da nova política nacional de saúde bucal (PNSB), denominada "Brasil Sorridente". No governo Lula, a saúde bucal foi declarada área estratégica e a Coordenação Nacional de Saúde Bucal recebeu apoio político e aporte financeiro para tirar do campo da teoria as aspirações da Saúde Bucal Coletiva no Brasil.

Pucca (2006) afirma que a PNSB é o resultado de anos de construção social, que teve nos momentos históricos que discutiram o modelo de saúde do Brasil, à saber: Reforma sanitária, 7 e 8 conferencias nacionais de saúde e 1,2 e 3 Conferencias nacionais de saúde bucal, importantes marcos históricos. O mesmo autor afirma que em 2004 a saúde bucal coletiva, enfim, começou a ver sair do papel o sonho de uma atenção à saúde bucal integral, em busca da universalidade e equidade, como reza a Constituição de 1988 e os desafios para romper com o modelo tradicional de assistência odontológica no SUS seriam enormes (Narvai; Frazão, 2009a,b). 
Para a organização deste novo modelo, alinhado à Política Nacional de saúde e baseado nos princípios da estratégia de saúde da família, Pucca (2006) ainda afirma que são fundamentais que sejam pensadas as linhas do cuidado da criança, do adolescente, do adulto, do idoso, com a criação de fluxos que impliquem ações resolutivas das equipes de saúde, centradas no acolher, informar, atender e encaminhar. A linha do cuidado implica um redirecionamento do processo de trabalho, no qual o bom funcionamento da equipe de trabalho é um de seus fundamentos mais importantes, e que a atenção em saúde bucal precisa romper com o modelo de atenção centrada exclusivamente no Cirurgião-dentista, que continua a ser o chefe da Equipe de Saúde Bucal (ESB), mas que tem em seus outros membros (técnicos e auxiliares) pessoas chave para viabilizar a o trabalho e as ações em saúde bucal. Para se adequar esse processo ao novo modelo é fundamental que se trabalhe os conceitos da interdisciplinaridade e multiprofissionalísmo, que devem ser pensadas e realizadas na lógica da integralidade da atenção, da intersetorialidade, ampliando a rede e qualificando a assistência. Para que a saúde bucal rompesse com o modelo passado e adequasse a atenção à saúde bucal aos preceitos constitucionais, a gestão central assumiu alguns compromissos: qualificar a atenção básica, assegurar integralidade das ações, utilizar a epidemiologia e as informações sobre o território para subsidiar o planejamento, centrar a atuação na vigilância em saúde, financiar e definir uma agenda de pesquisa científica (Narvai; Frazão, 2009a,b).

A PNSB e a proposta de um novo modelo de atenção em saúde bucal só têm avançado porque houve uma decisão política de reconhecimento do papel estratégico da SB na atenção integral à saúde e porque houve um financiamento considerável para área, já que a SB estava estagnada há anos e reverter o quadro encontrado em 2002, quando da eleição de Lula, só seria possível com um robusto financiamento.

O especial de saúde bucal, publicado no caderno de atenção básica, em 2008 , revela um modelo de atenção em saúde bucal, planejado em uma rede de atenção integrada, com característica poliárquicas, regionalizada e hierarquizada, tendo a atenção básica a responsabilidade de organização do usuário pelo interior do sistema e o mais importante, a saúde bucal está sendo, desde 2004, integrada ao SUS e às equipes de ESF, de modo a corrigir um dos maiores erros que a odontologia cometeu, que foi levar para o serviço público a lógica do trabalho autônomo privado, como foi o caso do dentista na escola (Brasil, 2008). 
Como parte importante da estratégia de expansão e adequação do modelo de atenção à saúde bucal no SUS, o aumento de ESB junto à ESF, tem proporcionado melhoria no acesso e tem permitido que o resto da rede se viabilize, lembrando que é a Atenção Primária à Saúde (APS), a responsável pela organização da rede, de modo prioritário. O número de ESB saltou de 4261 em 2002 para 22.139 em 2012, entretanto além do aumento de número de equipes, procurou-se espalhar a Atenção em saúde Bucal (ASB) pelo território nacional, portanto outro número expressivo, que demonstra a estruturação da rede é a presença de equipes por municípios, em 2012 os registros do MS indicavam que 4907 cidades possuíam pelo menos 1 equipe, este número era de apenas 2.302 em 2002. Como consequência deste incremento no número absoluto e no número relativo de ESB pelos municípios, a cobertura cresceu de 7\% em 2002 para 39\% em 2012.

A criação dos Centros de Especialidades Odontológica (CEO) foi um marco na atenção à saúde bucal no Brasil. Brasil (2008) afirma que a atenção especializada é um importante gargalo na atenção à saúde e não só na saúde bucal no Brasil. A criação, pela primeira vez na história do Brasil, de uma rede estruturada de atenção secundária foi tão importante para a saúde bucal, que apesar de nos parecer um erro, os CEOS se tornaram quase que sinônimo de Brasil Sorridente. Atualmente, a rede de atenção integrada à saúde bucal pode contar com a Atenção primária à Saúde Bucal (APSB), alocada na Unidade Básica de Saúde, ao lado de profissionais tais como médicos, enfermeiros, Agente Comunitário de Saúde (ACS), além do Técnico em Saúde Bucal(TSB) e Auxiliar em Saúde Bucal (ASB) e com atenção secundária mais dispersa pelo território da rede, respeitando o princípio da gestão de que recursos mais abundantes e com necessidade e demanda maior por parte da clientela deve ficar mais próximo do usuário e disperso no território, enquanto recursos mais escassos e com menor demanda devem ficar mais concentrados em determinados locais, nos quais o deslocamento não é fator tão decisivo (Narvai; Frazão, 2009a,b).

Ainda na média complexidade, a fim de superar e pagar parte de uma dívida histórica que temos com uma parte da população mutilada por uma Odontologia com práticas equivocadas, tendo em vista que mais de $70 \%$ dos idosos no Brasil são desdentados e na faixa etária de 30 a 44 anos, $30 \%$ dos adultos não tem um dente na boca, os LRPD são estrutura importante no contexto da rede de atenção à saúde e no novo modelo de atenção a SB proposto pelo MS. Atualmente, existe cerca de 1380 laboratórios, que necessitam de um investimento de mais de 8 MILHOES/MÊS. 
A alta complexidade em Odontologia sempre foi um nó crítico, pois outros atores entram neste cenário, com interesses diversos, entretanto o Brasil Sorridente tem enfrentado as resistências e tem aberto, de modo bem mais tímido é verdade, caminhos para a Odontologia no nível terciário de atenção. $O$ credenciamento de Centro de Alta Complexidade em Oncologia (Cacons) e a Unidade de Alta Complexidade em oncologia (Unacons) foi vinculado a presença do dentista na equipe, isso garante que os pacientes oncológicos tenham acesso à atenção odontológica antes, durante e depois de seu tratamento. Atualmente o Cirurgião Dentista (CD) pode internar pacientes, isso não era possível legalmente no passado. Também está na agenda do MS à ampliação dos atendimentos de pacientes com necessidades especiais sob sedação e anestesia geral, além de outros elementos da Odontologia Hospitalar.

Como se pode observar, os elementos básicos do modelo de atenção a SB proposto em 2004 são a APS, CEOS e Alta Complexidade, entretanto muitos outros atores e práticas são parte integrante deste processo. Deve-se lembrar que no modelo estão previstas atividades extra-clínicas, tais como as visitas domiciliares, levantamentos de necessidades, com referenciamentos de pacientes aos demais níveis, atendimentos e assistência domiciliar, atividades de educação em saúde.

Ainda, como citado acima, a atenção odontológica está organizada por ciclo de vida e grupos prioritários, a fim de trabalhar na lógica da universalidade, incluindo todos os grupos na atenção, mas organizando o fluxo por necessidade e risco e por ciclo de vida.

\subsection{GESTÃO EM SAÚDE: AVALIAÇÃO DE POLÍTICAS, PROGRAMAS E SERVIÇOS DE SAÚDE}

A gestão em saúde constitui-se como um conjunto de práticas administrativas com a finalidade de aperfeiçoar o funcionamento das organizações sejam pública ou privada, de grande, médio ou pequeno porte.

O que se pretende ao aplicar os conceitos e preceitos da gestão em saúde é que os serviços, políticas ou programas alcancem à máxima: eficiência, eficácia e efetividade (Fonte: elaboração própria.

Quadro 2.1). 


\begin{tabular}{|c|c|}
\hline \multicolumn{2}{|c|}{ Objetivos da Gestão em saúde é tornar o serviço } \\
\hline Eficiente & Relação entre produtos e recursos empregados \\
\hline Eficaz & Atingir os objetivos previamente estabelecidos \\
\hline Efetividade & Ser resolutivo \\
\hline
\end{tabular}

Fonte: elaboração própria.

Quadro 2.1 - Objetivos da Gestão em Saúde

Vivemos tempos em que a gestão em saúde se profissionalizou e há uma pressão para melhorar os processos, reduzir custo, aumentar a produção e aumentar a competitividade do serviço em relação ao mercado.

Para alcançar os novos patamares de gestão esperados, sejam no setor público ou privado, Pena e Malik (2011), sugerem etapas a serem cumpridas pelos gestores:

1. Análise do ambiente: Como avaliar os ambientes interno e externo, identificando potencialidade e ameaças ao processo.

2. Formulação de estratégia: Quais as formas adequadas para entrada no mercado e qual a posição que a organização pode ocupar neste cenário.

3. Execução da estratégia: Como traduzir a estratégia em ações e metas operacionais. Como construir a adequada implantação de serviços, programas e políticas.

4. Gerenciamento da estratégia: Como garantir controle adequado dos resultados obtidos.

Deve-se lembrar que a gestão estratégica não deve se distanciar do planejamento e da operação, e deve valorizar o fator humano como essencial na busca de resultados.

Uma grande aliada da gestão, que auxilia na melhoria da capacidade de tomada de decisão por parte do gestor é avaliação, que necessita ser aplicada constantemente durante o processo e que, no caso da saúde enfrenta alguns obstáculos. Os problemas decorrentes de programas, políticas e serviços de saúde com frequência exigem uma solução rápida que inviabiliza o processo de avaliação e 
este é sem dúvida um problema que dificulta a implantação de processos avaliativos em determinadas situações (Tanaka et al., 2012).

Tanaka et al. (2012) ainda afirma que os processos de avaliação encontram dificuldade de serem implantados e efetivados no setor da saúde tendo em vista a complexidade do processo saúde doença, a multicausalidade envolvida tanto na saúde quanto no adoecimento de uma pessoa ou de uma coletividade.

É possível dizer que o conceito de avaliação está intimamente ligado ao processo de tomada de decisão, elemento fundamental da gestão em saúde, entretanto, é possível afirmar também que a avaliação pode ser um processo que instrumentalize um julgamento de valores, sem que se tenha claro o efeito que isso vai causar.

O que observa-se, na prática, da Saúde Coletiva e da gestão em saúde é que avaliações, sejam fomentadas por pesquisas científicas, sejam oriundas da própria gestão, são realizadas com intuito de subsidiar a tomada de decisão e, portanto, este parece ser um objeto próprio da gestão, ou seja, em diversos momentos é observado uma complementariedade entre gestão e avaliação, como se ambas fossem indissociáveis.

O processo de avaliação não fácil no setor da saúde, visto que sempre haverá conflitos entre os profissionais da saúde e a própria gestão. Os primeiros não se sentem confortáveis em ser avaliados, já que sua formação não os preparou para isso e a segunda não conhece todos os passos da atenção e da assistência e estes fatos geram tensões que precisam ser minimizadas. Existe a necessidade de acrescentar a este cenário atores tais como pacientes, investidores, governos, mídia e opinião pública, fornecedores e grandes empresas com poder econômico, políticos e interesses diversos. Percebe-se que fazer avaliação para subsidiar gestão em saúde não é tarefa fácil e exige grande habilidade por parte de avaliadores, entretanto a tomada de decisão é uma responsabilidade formal do gestor, que se pauta além dos resultados obtidos nas avaliações, podem respaldar-se em suas experiências pessoais e profissionais, interesses políticos e econômicos, demanda e pressão dos diversos atores que compõem o complexo cenário da gestão em saúde. Isto significa que a avaliação deve ser compreendida como um instrumento ou ferramenta da gestão para enfrentar e resolver um problema do serviço ou do programa de saúde, ou seja, tem por finalidade propiciar um processo de decisão oportuno em um 
determinado tempo, com confiabilidade e abrangência de informações, segundo objetivos das distintas audiências" (Tanaka; Melo, 2008).

A essência da avaliação é subsidiar a tomada de decisão e tornar factível o processo de mudança que pode se originar dela, portanto, Tanaka sugere que se for necessário, a avaliação deve ser redimensionada, deve-se limitar sua aplicabilidade ao local, serviço ou programa específico, simplificando processos, relativizando resultados e baixando custos.

Miranda (2005) afirma que o propósito primordial da gestão em saúde é a produção de decisões, que desencadeiam o processo de intermediação e implantação das políticas.

Tratando especificamente da saúde pública não pode-se esquecer que o Brasil em 2006 estabeleceu documentos denominados pactos que definiram claramente diretrizes a serem seguidas no âmbito do SUS, o pacto pela vida, o pacto em defesa do SUS e o pacto de gestão, e este último estabelece as responsabilidades claras de cada nível de governo, de forma a diminuir as competências concorrentes e a tornar mais claro quem deve fazer o quê, contribuindo, assim, para o fortalecimento da gestão compartilhada e solidária do SUS. Reforça a descentralização, estabelece como prioritária a territorialização da saúde como base para organização dos sistemas, instituindo colegiados de gestão regional. Reitera a importância da participação e do controle social com o compromisso de apoiar à sua qualificação explicita as diretrizes para o sistema de financiamento público tripartite, buscando critérios de alocação equitativa dos recursos; estabelece cinco grandes blocos de financiamento: atenção básica, média e alta complexidade da assistência à saúde, vigilância em saúde, assistência farmacêutica e gestão do SUS. Por fim, estabelece as diretrizes para a gestão do SUS, com ênfase na Descentralização; Regionalização; Financiamento; Programação Pactuada e Integrada; Regulação; Participação e Controle Social; Planejamento; Gestão do Trabalho e Educação na Saúde.

Em relação ao conjunto de responsabilidades do Pacto de Gestão, fica claro que é competência da gestão, também, o desenvolvimento do processo de monitoramento e avaliação, a partir das necessidades de saúde, portanto estamos tratando de algo pactuado, valorizado pelo SUS e que recebe financiamento específico ao lado de áreas estratégicas, tais como Atenção básica, vigilância, dentre outros, entretanto o próprio Ministério da saúde reconhece que o processo de avaliação em saúde ainda apresenta a maioria de experiências incipientes, sem uma 
abrangência de resultados que permita a aplicação dos achados em outras situações e ou amostras e que ainda temos muito que avançar nesta área.

No âmbito do SUS e da atenção em saúde bucal no Brasil, os processos de avaliação passam necessariamente pelos sistemas de informação, que sistematizam dados e fornecem poderosos instrumentos de análises e avaliação. O Sistema de Informação da Atenção Básica (SIAB), por exemplo, fornece alguns dados que têm servido de parâmetro da gestão local e central, tais como: a tendência de cobertura de tratamento, através do registro de dados de primeira consulta e a cobertura relativa de procedimentos coletivos para população de 0 a 14 anos de um território, mensurado através do registro e monitoramento do número de Procedimentos Coletivos (PC) realizados em 1 ano em um determinado local.

O Sistema de informação ambulatorial (SIA-SUS) fornece dados importantes que dizem respeito, fundamentalmente, ao número de procedimentos no âmbito ambulatorial que a saúde bucal prestou e subsidia a avaliação dos serviços no que diz respeito à produção e ao tipo de procedimentos realizados, dentre outros.

Um dos nós-críticos a serem superados nos sistemas de informação à saúde é o preenchimento completo e correto das fichas pelos profissionais de saúde, e gerência dos serviços, já que o preenchimento de forma completa e fidedigna permite a obtenção de indicadores de várias naturezas (de modelo de atenção, de efetividade, de eficiência, de eficácia e de qualidade) que tornam possível o acompanhamento dos serviços de saúde bucal, traduzem a necessidade de forma indireta das condições de saúde bucal da população usuária e podem reafirmar e subsidiar a constante demanda por ampliação da rede de serviços na atenção básica ou na rede especializada, destacando a necessidade de ampliação dos quadros de recursos humanos.

Outro importante instrumento que pauta a tomada em decisão por parte da gestão e que participa dos processos de avaliação de serviços, políticas e programas são os levantamentos epidemiológicos, que em saúde bucal tem como figuras centrais os levantamentos de 2002 e 2010, mas dados como os CENSOs, PNAD, informações como mortalidade infantil, notificação de câncer, morte por câncer, índice de Desenvolvimento Humano (IDH), dentre outros devem ser alvo de estudo na gestão em SB, já que esta deve ser tratada e sua complexidade, levando em conta a determinação social das doenças bucais e tendo a integralidade como diretriz tanto da gestão como do planejamento em SB. 
Também é observado na literatura que além da pesquisa quantitativa, métodos qualitativos têm sido aplicados para avaliação de processos e para captar a percepção dos atores envolvidos no cuidado à saúde, grupos focais, entrevista com atoreschave, groundes theory, fenomenologia, dentre outras metodologias de coleta de dados e análises de dados tem sido aplicadas na avaliação de serviços, programas e políticas e fornecem dados não quantitativos, que dizem respeito à subjetividade envolvida no trabalho em saúde, na atenção à saúde e no cuidado de pessoas.

Por fim, discutir gestão em saúde bucal e avaliação de políticas, programas e serviços deve passar necessariamente pela gestão de pessoas. Deve-se lembrar que a produção, os processos e serviços são efetivados, ou não, pelos servidores e esses devem ser prestigiados pela gestão. Motivar os recursos humanos, dar condições de trabalho digna, remunerar de forma satisfatória, qualificara rede, são alguns dos desafios da gestão para alcançar a efetividade, a eficácia, a eficiência e a qualidade da atenção em saúde bucal nos próximos anos (Pucca, 2006)

Neste contexto, o sistema único saúde, após sua fase de implantação e fortalecimento, tem se submetido a um sistemático e complexo sistema de avaliação denominado Programa Nacional de Melhoria do Acesso e da Qualidade da Atenção Básica (PMAQ-AB) (Brasil, 2013 a,b).

\subsection{PROGRAMA NACIONAL DE MELHORIA DE ACESSO E DA QUALIDADE DA ATENÇÃO BÁSICA}

Devida à cobertura estimada em mais da metade da população brasileira pela Estratégia Saúde da Família (ESF), e com intuito induzir a ampliação do acesso da Atenção Básica, com garantia de um padrão de qualidade, bem como permitir maior transparência e efetividade das ações governamentais direcionadas à Atenção Básica de Saúde, o Ministério da Saúde (MS) institui o Programa de Melhoria do Acesso e Qualidade na Atenção Básica (PMAQ-AB), tendo como principal objetivo estimular a ampliação da capacidade das gestões federal, estaduais e municipais, além das Equipes de Atenção Básica (EAB) e ,em ofertar os serviços de acordo com as 
necessidades concretas da população. Ele se dá por meio de avaliação e monitoramento da atenção básica, e está atrelado a um incentivo financeiro para as gestões municipais que aderirem ao programa (Brasil, 2011; Brasil, 2012a,b,c,d;e; Pereira et al., 2013; Reis et al., 2012; Brasil, 2013c; Azevedo et al., 2013; Barros, 2013; Barroso et al., 2013; Pinto, 2012; Pinto et al. 2012; Tanus et al., 2013). Atualmente são mais de 100 milhões de brasileiros assistidos pela Atenção Básica, com 38mil Unidades Básicas de Saúde e 600 mil profissionais atuando em todos os municípios do país (Brasil, 2013).

Segundo Brasil (2011),

A Portaria 1.654 do Ministério da Saúde, publicada em 19 de julho de 2011, criou o Programa Nacional de Melhoria do Acesso e da Qualidade (PMAQ$A B)$ e vinculou pela primeira vez 0 repasse de recursos à implantação $e$ alcance de padrões de acesso e de qualidade pelas equipes de atenção básica (EAB). Essa medida representa um processo profundo de mudança na lógica de repasse de recursos para a Atenção Básica $(A B)$ e anuncia mudanças semelhantes no financiamento do Sistema Único de Saúde (SUS) como um todo.

Segundo Brasil (2012d, p. 8),

Dentre os objetivos específicos podem ser destacados:

I - Ampliar o impacto da $A B$ sobre as condições de saúde da população e sobre a satisfação dos seus usuários, por meio de estratégias de facilitação do acesso e melhoria da qualidade dos serviços e ações da AB;

II - Fornecer padrões de boas práticas e organização das UBS que norteiem a melhoria da qualidade da $A B$;

III - Promover maior conformidade das UBS com os princípios da AB, aumentando a efetividade na melhoria das condições de saúde, na satisfação dos usuários, na qualidade das práticas de saúde e na eficiência e efetividade do sistema de saúde;

IV - Promover a qualidade e inovação na gestão da $A B$, fortalecendo os processos de auto avaliação, monitoramento e avaliação, apoio institucional e educação permanente nas três esferas de governo;

V - Melhorar a qualidade da alimentação e uso dos sistemas de informação como ferramenta de gestão da $A B$;

VI - Institucionalizar uma cultura de avaliação da AB no SUS e de gestão com base na indução e acompanhamento na de processos e resultados; e,

$\mathrm{VI}$ - Estimular o foco da $A B$ no usuário, promovendo a transparência dos processos de gestão, a participação e controle social e a responsabilidade sanitária dos profissionais e gestores de saúde com a melhoria das condições de saúde e satisfação dos usuários. 
O mesmo documento cita na p. 9, os principais desafios para qualificação da $A B$ pelo $P M A Q-A B:$

I - Precariedade da rede física, com parte expressiva de UBS em situação inadequada;

II - Ambiência pouco acolhedora das UBS, transmitindo aos usuários uma impressão de que os serviços ofertados são de baixa qualidade e negativamente direcionados à população pobre;

III - Inadequadas condições de trabalho para os profissionais, comprometendo sua capacidade de intervenção e satisfação com o trabalho;

IV - Necessidade de qualificação dos processos de trabalho das equipes de $A B$, caracterizados, de maneira geral, pela sua baixa capacidade de realizar o acolhimento dos problemas agudos de saúde; pela insuficiente integração dos membros das equipes; e pela falta de orientação do trabalho em função de prioridades, metas e resultados, definidos em comum acordo pela equipe, gestão municipal e comunidade;

$V$ - Instabilidade das equipes e elevada rotatividade dos profissionais, comprometendo o vínculo, a continuidade do cuidado e a integração da equipe;

VI - Incipiência dos processos de gestão centrados na indução e acompanhamento da equidade;

VII - Sobrecarga das equipes com número excessivo de pessoas sob sua responsabilidade, comprometendo cobertura e qualidade de suas ações;

VIII - Pouca integração das equipes de $A B$ com a rede de apoio diagnóstico e terapêutico e com os outros pontos da Rede de Atenção à Saúde (RAS);

IX - Baixa integralidade e resolutividade das práticas, com a persistência do modelo de queixa-conduta, de atenção prescritiva, procedimento-médicocentrada, focada na dimensão biomédica do processo saúde-doençacuidado;

$X I$ - Financiamento insuficiente e inadequado da $A B$, vinculado ao credenciamento de equipes, independentemente dos resultados e da melhoria da qualidade."

Segundo Pinto et al. (2012), o programa só é possível mobilizando os atores locais, estimulando a mudança das condições e práticas de atenção, gestão e participação, tendo como norte as diretrizes pactuadas nacionalmente. Para tanto, existe a necessidade de se formar espaços de diálogos, problematização, negociação e gestão da mudança entre equipes, gestores e usuários. A magnitude do programa e sua complexidade ficam evidenciadas nas diretrizes expostas no Artigo $2^{\circ}$ da Portaria 1.654, de 19 de Julho de 2011 (Brasil, 2011): 
Art. 2ํㅗ̃o diretrizes do PMAQ-AB:

I - construir parâmetro de comparação entre as equipes de saúde da atenção básica, considerando-se as diferentes realidades de saúde;

II - estimular processo contínuo e progressivo de melhoramento dos padrões e indicadores de acesso e de qualidade que envolva a gestão, o processo de trabalho e os resultados alcançados pelas equipes de saúde da atenção básica;

III - transparência em todas as suas etapas, permitindo-se o contínuo acompanhamento de suas ações e resultados pela sociedade;

IV - envolver, mobilizar e responsabilizar os gestores federal, estaduais, do Distrito Federal e municipais, as equipes de saúde de atenção básica e os usuários num processo de mudança de cultura de gestão e qualificação da atenção básica;

V - desenvolver cultura de negociação e contratualização, que implique na gestão dos recursos em função dos compromissos e resultados pactuados e alcançados;

VI - estimular a efetiva mudança do modelo de atenção, o desenvolvimento dos trabalhadores e a orientação dos serviços em função das necessidades e da satisfação dos usuários; e

VII - caráter voluntário para a adesão tanto pelas equipes de saúde da atenção básica quanto pelos gestores municipais, a partir do pressuposto de que o seu êxito depende da motivação e pro atividade dos atores envolvidos.

As fases de implantação do PMAQ-AB são contínuas e determinadas por um ciclo organizado por quatro fases que se completam (Brasil, 2011, 2012a,b,c,d,e; 2013; Azevedo et al., 2013, Pinto, 2012).

1. Adesão e Contratualização:

2. Desenvolvimento;

3. Avaliação Externa;

4. Recontratualização.

Vale ressaltar que a adesão ao programa é voluntária tanto para as Equipes de Atenção Básica como para os gestores municipais, como estímulo a participação no programa os municípios recebem um acréscimo no repasse do Piso da Atenção Básica Variável (PAB) (Azevedo et al., 2013, Pinto et al., 2012). Segundo Brasil (2012d) e Pinto et al. (2013), a qualificação do serviço e as mudanças das práticas só 
ocorrem em ambientes que os trabalhadores sintam-se estimulados e percebam as necessidades para o êxito.

\subsubsection{Adesão e Contratualização}

A Primeira fase (adesão e contratualização) é descrita como a etapa formal de adesão do programa, é realizada através do sistema de gestão de programas do departamento da atenção básica (SGDAB), (Brasil, 2012d), mediante a contratualização de indicadores e compromissos a serem firmados entre as Equipes de Atenção Básica e os gestores municipais, e desses com o Ministério da Saúde, num processo que envolve pactuação regional e estadual e a participação do controle social. Todas as Equipes da Atenção Básica, incluindo as Equipes de Saúde Bucal (ESB), independente do modelo que se organizam, podem aderir ao PMAQ--AB, desde que estejam em conformidade com os princípios da atenção básica, universalidade, integralidade, equidade, descentralização e participação popular. Formalizando a adesão ao programa, o município pode incluir todas ou apenas uma parte das equipes no programa. A informação sobre a adesão do município deve ser encaminhada ao Conselho Municipal de Saúde e à Comissão Intergestores Regional, com posterior homologação na Comissão Intergestores Bipartite. (Brasil, 2011, 2012d).

Após a adesão, o município passa a receber mensalmente $20 \%$ do componente de qualidade do PAB Variável, fundo a fundo, por EAB participante. $O$ valor corresponde a $\mathrm{R} \$ 6.500,00$ por $E A B$, podendo chegar a $R \$ 8.500,00$ quando houver Equipe de Saúde bucal vinculado à EAB. Desse modo, cada município receberá, ao aderir ao programa, $\mathrm{R} \$ 1.300,00$ por $\mathrm{EAB}$ e $\mathrm{R} \$ 1.700,00$ quando houver $\mathrm{ESB}$ vinculada à $E A B$. Após o processo de avaliação externa do programa, previsto para a fase quatro, o valor a ser transferido por EAB será vinculado ao seu desempenho, podendo ser de cem por cento no caso de desempenho ótimo, ou suspensão no caso de desempenho insatisfatório (Brasil 2011, 2012d, Azevedo et al., 2013, Pinto et al., 2013). 
Também serão descredenciados os municípios que não formalizarem o pedido de avaliação externa no período máximo de seis meses para o primeiro ciclo e dezoito meses para os próximos ciclos do programa. Nestes casos o município ficará impedido de participar do PMA-AB por dois anos (Brasil, 2011, 2012d).

Para Brasil (2011), a permanência das equipes da atenção básica ao programa fica condicionada:

I - Às mesmas exigências que disciplinam o pagamento do PAB Variável previstas na Política Nacional de Atenção Básica vigente. Entre elas, destacase o cadastramento e atualização regular, por parte dos gestores, de todos os profissionais das equipes de atenção básica no Cadastro Nacional de Estabelecimentos de Saúde (CNES), assim como o cumprimento da carga horária de acordo com o informado;

II - À alimentação mensal do Sistema de Informação da Atenção Básica (SIAB), inclusive do novo relatório PMA2-Complementar, por meio da utilização do transmissor simultâneo pelo município, para o envio da base de dados do Siab; do Sistema de Vigilância Alimentar e Nutricional (Sisvan); e do Módulo de Gestão do Programa Bolsa-Família na Saúde, permitindo, com isso, o efetivo monitoramento dos indicadores contratualizados no âmbito do programa;

III - À não piora em mais de um desvio-padrão por três meses ou mais no escore dos indicadores de monitoramento alcançado e considerado no processo de certificação;

IV - À não verificação, por órgãos de controle e sistema nacional de auditoria, de que as condições certificadas não estão mais presentes, devendo, nesse caso, ser realizado processo conforme as disposições do sistema nacional de auditoria;

V - À garantia, por gestores e equipes, da identificação visual estabelecida pelo Ministério da Saúde, contendo informações tais como a carteira de serviços ofertados pela equipe, o horário de funcionamento da Unidade Básica de Saúde, o nome e escala dos profissionais, o telefone da ouvidoria do município (quando houver) e do Ministério da Saúde, além do endereço na internet em que se encontram informações a respeito dos resultados alcançados pela equipe.

O processo de contratualização prevê:

1 - A assinatura de um Termo de Compromisso (TC) por parte da(s) equipe(s) de atenção básica com a gestão municipal;

2 - A assinatura de um TC entre a gestão municipal e o Ministério da Saúde no processo de adesão, que tem como pré etapa a contratualização da gestão com suas equipes;

3 - A assinatura de um TC e/ou uma resolução da A Comissão Intergestores Bipartite $(\mathrm{CIB})$ prevendo compromissos firmados entre a gestão municipal e estadual, para o apoio e participação no PMAQ-AB. 
Ao completar a etapa de contratualização no sistema de adesão ao PMAQ-AB, os municípios e as equipes assumem compromissos voltados para a melhoria do acesso e qualidade no âmbito da atenção básica São compromissos das equipes e dos três entes de gestão:

\subsubsection{Compromissos}

1- Compromissos das equipes de atenção básica (Brasil, 2012d).

i. Organizar o processo de trabalho da equipe em conformidade com os princípios da atenção básica previstos no Programa Nacional de Melhoria do Acesso e da Qualidade da Atenção Básica e na PNAB;

ii. Implementar processos de acolhimento à demanda espontânea para a ampliação, facilitação e qualificação do acesso;

iii. Alimentar o Sistema de Informação da Atenção Básica (SIAB) de forma regular e consistente, independentemente do modelo de organização da equipe;

iv. Programar e implementar atividades, com a priorização dos indivíduos, famílias e grupos com maior risco e vulnerabilidade;

v. Instituir espaços regulares para a discussão do processo de trabalho da equipe e para a construção e acompanhamento de projetos terapêuticos singulares;

vi. Instituir processos autoavaliativos como mecanismos disparadores da reflexão sobre a organização do trabalho da equipe, com participação de todos os profissionais que constituem a equipe;

vii. Desenvolver ações intersetoriais voltadas para o cuidado e a promoção da saúde;

viii. Pactuar metas e compromissos para a qualificação da atenção básica com a gestão municipal.

2 - Compromissos das gestões municipais (Brasil, 2012d):

i. Garantir a composição mínima da(s) equipe(s) de atenção básica participante(s) do programa, com seus profissionais devidamente cadastrados no Cadastro Nacional dos Estabelecimentos de Saúde (CNES);

ii. Manter alimentação regular e consistente do Sistema de Informação da Atenção 
Básica (SIAB), com informações referentes à(s) equipe(s) de atenção básica participante(s) do programa, permitindo o seu monitoramento permanente;

iii. Garantir oferta mínima de ações de saúde para a população coberta por equipe de atenção básica, de acordo com a Política Nacional de Atenção Básica (PNAB) e traduzidas pelos indicadores e padrões de qualidade definidos pelo programa;

iv. Aplicar os recursos do Componente de Qualidade do PAB Variável em ações que promovam a qualificação da atenção básica;

v. Estruturar a Coordenação de Atenção Básica, constituindo e garantindo condições de funcionamento da equipe de gestão responsável pela implantação local do programa;

vi. Instituir processos de autoavaliação da gestão e da(s) equipe(s) de atenção básica participante(s) do programa;

vii. Definir o território de atuação das Unidades Básicas de Saúde (UBS) e a população adscrita por equipe de atenção básica;

viii. Implantar apoio institucional e matricial à(s) equipe(s) de atenção básica do município;

ix. Realizar ações de educação permanente com/para a(s) equipe(s) de atenção básica;

x. Implantar processo regular de monitoramento e avaliação, para acompanhamento e divulgação dos resultados da atenção básica no município;

xi. Realizar ações para a melhoria das condições de trabalho da(s) equipe(s) de atenção básica;

xii. Apoiar a instituição de mecanismos de gestão colegiada nas Unidades Básicas de Saúde;

xiii. Solicitar ao Ministério da Saúde avaliação externa das equipes de atenção básica participantes do programa, nos prazos estipulados;

xiv. Apoiar a realização do processo de avaliação externa das equipes de atenção básica participantes do programa, oferecendo condições logísticas de hospedagem e transporte para a equipe de avaliadores externos.

\section{3 - Compromissos das gestões estaduais (Brasil, 2012d):}

i. Instituir mecanismos de apoio institucional aos municípios participantes do programa, para potencializar os processos de melhoria do acesso e da qualidade da atenção básica;

ii. Implantar processo regular de monitoramento e avaliação, para acompanhamento e divulgação dos resultados da atenção básica no Estado;

iii. Ofertar ações de educação permanente e outras estratégias de qualificação da gestão, do cuidado e da gestão do cuidado; 
iv. Pactuar, com a Comissão Intergestores Bipartite, estratégias e diretrizes para a implementação do programa no Estado, de acordo com suas diretrizes;

v. Estimular e promover o intercâmbio de experiências entre os diversos municípios, para disseminar tecnologias e conhecimentos voltados para a melhoria do acesso e da qualidade da atenção básica;

vi. Contribuir com a coordenação nacional do processo de avaliação externa a que devem ser submetidas as equipes participantes do programa, por meio do Conass;

vii. Realizar estudos sobre a viabilidade técnica e financeira para o estabelecimento ou orientação dos mecanismos de co-financiamento estadual da atenção básica, em convergência com a Política Nacional de Atenção Básica.

\section{4 - Compromissos do Ministério da Saúde:}

i. Assegurar a efetiva implementação do programa no âmbito nacional, estadual, do

Distrito Federal e municipal;

ii. Transferir regularmente os recursos referentes ao Componente de Qualidade do PAB Variável, de acordo com as regras do programa;

iii. Efetuar a análise do cumprimento das condições de adesão e de permanência dos municípios no programa;

iv. Elaborar instrumentos e promover processos de apoio institucional para subsidiar a implantação do programa;

v. Ofertar ações de educação permanente e outras estratégias de qualificação da gestão, do cuidado e da gestão do cuidado;

vi. Implantar processo regular de monitoramento e avaliação, para acompanhamento e divulgação dos resultados da atenção básica no País;

vii. Realizar avaliações que orientem o aperfeiçoamento do programa e ampliem sua capacidade de gestão e de adequação às necessidades dos atores envolvidos em sua implementação;

viii. Financiar e coordenar (de maneira tripartite) o processo de avaliação externa a que devem ser submetidas às equipes participantes do programa;

ix. Coordenar o processo de recontratualização de ações para melhoria da qualidade da atenção básica, de maneira singularizada com cada equipe de atenção básica participante do programa, a partir do seu desempenho no processo de certificação." (Brasil, 2012). 
2.4.1.2 Indicadores firmados na contratualização

Nos compromissos é pactuado um conjunto de 47 indicadores (quadro $2.2 \mathrm{e}$ 2.3) entre as equipes participantes e pela gestão municipal. $O$ instrumento utilizado é o SIAB, que é o único instrumento disponível para ser utilizada para avaliar as equipes individualmente, além de permitir a alimentação de dados cadastrais, a análise da suficiência e adequação da oferta de serviços a algumas necessidades específicas da população coberta pela equipe avaliada (Brasil, 2012d).

Os indicadores foram divididos em sete áreas estratégicas, classificados por indicadores de desempenho, vinculados ao processo de certificação e que serão utilizados para a classificação das equipes, conforme o seu desempenho e indicadores de monitoramento, a serem acompanhados de forma regular para complementação de informações sobre a oferta de serviços e resultados alcançados por cada equipe, sem, no entanto, influenciar na pontuação atribuída às $E A B$ no processo de avaliação externa (Brasil, 2011, Brasil, 2012d, Savassi, 2012, Brasil, 2013 b). 


\begin{tabular}{|c|c|c|}
\hline $\begin{array}{c}\text { ÁREA } \\
\text { ESTRATÉGICA }\end{array}$ & & INDICADORESDEDESEMPENHO \\
\hline \multirow{6}{*}{$\begin{array}{l}\text { 1.SAÚDE DA } \\
\text { MULHER }\end{array}$} & 1.1 & Proporção de gestantes cadastradas pela equipe de atenção básica \\
\hline & 1.2 & Média de consultas de pré-natal por gestante cadastrada \\
\hline & 1.3 & Proporção de gestantes que iniciaram o pré-natal no primeiro trimestre \\
\hline & 1.4 & Proporção de gestantes com o pré-natal no mês \\
\hline & 1.5 & Proporção de gestantes com vacina em dia. \\
\hline & & $\begin{array}{l}\text { Proporção de mulheres com exame citopatológico do colo do útero realizado na faixa } \\
\text { etária de } 15 \text { anos ou mais }\end{array}$ \\
\hline \multirow{6}{*}{$\begin{array}{l}\text { 2.SAÚDE DA } \\
\text { CRIANÇA }\end{array}$} & 2.1 & Média de consultas de puericultura por criança cadastrada \\
\hline & 2.2 & Proporção de crianças menores de quatro meses com aleitamento exclusivo \\
\hline & 2.3 & Proporção de crianças menores de um ano com vacina em dia \\
\hline & 2.4 & Proporção de crianças menores de dois anos pesadas \\
\hline & 2.5 & Média de consultas médicas para menores de um ano \\
\hline & 2.6 & Média de consultas médicas para menores de cinco anos \\
\hline \multirow{4}{*}{$\begin{array}{l}\text { 3.DOENÇAS } \\
\text { CRÔNICAS }\end{array}$} & 3.1 & Proporção de pessoas com diabetes cadastradas \\
\hline & 3.2 & Proporção de pessoas com hipertensão cadastradas \\
\hline & 3.3 & Média de atendimentos por diabético \\
\hline & 3.4 & Média de atendimentos por hipertenso \\
\hline \multirow{4}{*}{$\begin{array}{l}\text { 4.PRODUÇÃO } \\
\text { GERAL }\end{array}$} & 4.1 & Média de consultas médicas por habitante \\
\hline & 4.2 & Proporção de consultas médicas para cuidado continuado/programado \\
\hline & 4.3 & Proporção de consultas médicas de demanda agendada \\
\hline & 4.4 & Proporção de consultas médicas de demanda imediata \\
\hline
\end{tabular}

Fonte: Programa Nacional de Melhoria de Acesso e Qualidade de Atenção Básica 


\begin{tabular}{|c|c|}
\hline ÁREA ESTRATÉGICA & INDICADORESDEMONITORAMENTO \\
\hline 1.SAÚDE DA MULHER & Proporção de gestantes acompanhadas por meio de visitas domiciliares. \\
\hline \multirow{3}{*}{ 2.SAÚDE DA CRIANÇA } & Proporção de crianças com baixo peso ao nascer; \\
\hline & Proporção de crianças menores de um ano acompanhadas no domicílio; \\
\hline & $\begin{array}{c}\text { Cobertura de crianças menores de 5anos de idade no Sistema de Vigilância } \\
\text { Alimentar e Nutricional (SISVAN). }\end{array}$ \\
\hline \multirow{2}{*}{$\begin{array}{l}\text { 3.DOENÇAS } \\
\text { CRÔNICAS }\end{array}$} & Proporção de diabéticos acompanhados no domicílio; \\
\hline & Proporção de hipertensos acompanhados no domicílio. \\
\hline \multirow{8}{*}{ 4.PRODUÇÃO GERAL } & Proporção de consultas médicas de urgência com observação; \\
\hline & Proporção de encaminhamentos para atendimento de urgência e emergência; \\
\hline & Proporção de encaminhamentos para atendimento especializado. \\
\hline & Proporção de encaminhamentos para internação hospitalar; \\
\hline & Média de exames solicitados por consulta médica básica; \\
\hline & Média de atendimentos de enfermeiro; \\
\hline & $\begin{array}{l}\text { Média de visitas domiciliares realizadas pelo Agente Comunitário de Saúde(ACS) } \\
\text { por família cadastrada; }\end{array}$ \\
\hline & $\begin{array}{l}\text { Proporção de acompanhamento das condicionalidades de } \\
\text { saúdepelasfamíliasbeneficiáriasdoProgramaBolsaFamília }\end{array}$ \\
\hline \multirow{2}{*}{$\begin{array}{l}\text { 5.DOENÇAS } \\
\text { TRANSMISSIVEIS }\end{array}$} & Média de atendimentos de tuberculose; \\
\hline & Média de atendimentos de hanseníase. \\
\hline \multirow{4}{*}{ 6.SAÚDE MENTAL } & Proporção de atendimentos em Saúde Mental exceto usuários de álcool e drogas; \\
\hline & Proporção de atendimentos de usuário de álcool; \\
\hline & Proporção de atendimentos de usuário de drogas; \\
\hline & Taxa de prevalência de alcoolismo \\
\hline
\end{tabular}

Fonte: Programa Nacional de Melhoria de Acesso e Qualidade de Atenção Básica

Quadro 2.3 - Indicadores de monitoramento 
Para as Equipes de Saúde Bucal Foram utilizados sete indicadores (quadro 2.4):

\begin{tabular}{|l|}
\hline INDICADORESDEDESEMPENHO \\
\hline 1. Média de ação coletiva de escovação dental supervisionada \\
\hline 2. Cobertura de primeira consulta odontológica programática \\
\hline 3. Proporção de instalações de próteses dentárias \\
\hline 4. Razão entre tratamentos concluídos e 1as consultas odontológicas programáticas \\
\hline INDICADORES DE MONITORAMENTO \\
\hline 1. Cobertura de atendimento odontológico à gestante \\
\hline 2. Média de atendimentos de urgência odontológica por habitante \\
\hline 3. Taxa de incidência de alterações da mucosa oral. \\
\hline
\end{tabular}

Fonte: Programa Nacional de Melhoria de Acesso e Qualidade de Atenção Básica

Quadro 2.4 - Indicadores para as Equipes de Saúde Bucal

Tendo como entendimento que a Estratégia Saúde da Família é uma opção do fortalecimento da Atenção Básica, e que nem todos os municípios aderiram totalmente ou parcialmente a estratégia, por possuiriam redes de Atenção Básica implantada anteriormente, o Ministério da Saúde elaborou parâmetros mínimos para as EAB que se organizam de forma diferente a ESF: "Critérios de Parametrização e Equivalência das Diferentes Modalidades de Organização da Atenção Básica com a Estratégia Saúde da Família" (Brasil, 2012d).

\subsubsection{Desenvolvimento}

A segunda fase (desenvolvimento) é compreendida como a etapa no qual se dá desenvolvimento das ações, que são realizadas pelas EAB e gestão municipal, mas com o apoio das gestões estaduais e Ministério da Saúde, com o intuito de promover os movimentos de mudança da gestão, do cuidado e da gestão do cuidado que produzirão a melhoria do acesso e da qualidade da Atenção Básica. Esta fase está organizada em quatro dimensões: auto avaliação, monitoramento, educação permanente e apoio institucional (Brasil, 2012d; Fontenelle, 2012; Pinto et al. 2013). 


\subsubsection{Auto Avaliação}

É o ponto de partida da fase de desenvolvimento, onde os sujeitos e grupos implicados iniciam o processo de identificação e reconhecimento das dimensões positivas e problemáticas do seu trabalho, formulando estratégias de intervenção para melhoria dos serviços, das relações e processos de trabalho. O programa estimula o coletivo e em analisar os processos e resultados dos seus trabalhos, identificando os problemas e pactuar, por esse mesmo coletivo, a superação dos problemas e alcançar os objetivos propostos (Brasil 2012d, 2012b, 2012c; Pinto et al.).

Para tanto, o Ministério da Saúde ofertou a ferramenta validada nacionalmente e internacionalmente, "Autoavaliação para a melhoria do acesso e da qualidade (AMAQ), que pode ser utilizado em combinação com outros instrumentos avaliativo, pactuado com o município, para adequação da necessidade da realidade, Avaliação para Melhoria da Qualidade (AMQ), PrimaryCareAssessment Tool (PCATool), Quality book ofTools (Brasil 2011; 2012d,c; Fontenelle, 2012; Pinto et al.).

O instrumento Autoavaliação para Melhoria do Acesso e Qualidade da Atenção Básica AMAQ-AB foi construído considerando ainda as seguintes diretrizes (Brasil 2012d):

I-Refletir os objetivos centrais e diretrizes do Programa Nacional de Melhoria do Acesso e da Qualidade da Atenção Básica;

II - Ser capaz de promover reflexões sobre as responsabilidades, tanto no que se refere à forma de organização e à prática de trabalho dos atores envolvidos na gestão municipal e equipes de atenção básica, com vistas a promover o acesso com qualidade aos serviços oferecidos;

III - Estimular a efetiva mudança do modelo de atenção e o fortalecimento da orientação dos serviços em função das necessidades e satisfação dos usuários;

IV - Refletir padrões de qualidade que tenham caráter incremental em si mesmo, cuja adequação da situação analisada se dá por meio de escala numérica; e

V - Possibilitar a quantificação das respostas auto avaliativas, de maneira a viabilizar a constituição de escores gerais de qualidade. 
O instrumento é dividido em duas partes de acordo com a competência, gestão ou equipe, com padrões definidos diretamente com a competência dos autores envolvidos: gestão, coordenação e equipe de atenção básica, que subdividem em 13 subdimensões (quadro 2.5) se estas, em padrões que abrangem o que é esperado em termos de qualidade para a atenção básica, referindo-se a uma visão ampla do sistema e das ações em saúde e por serem capazes de evidenciar mudanças, tanto os avanços como os retrocessos (Brasil 2012d, 2012c).

\begin{tabular}{|c|c|c|}
\hline \multirow{9}{*}{ Gestão } & \multirow{4}{*}{ Gestão municipal } & Implantação e implementação da atenção básica no município \\
\hline & & Organização e integração da rede de atenção à saúde \\
\hline & & Gestão do trabalho \\
\hline & & Participação, controle social e satisfação do usuário \\
\hline & \multirow{3}{*}{ Coordenação da Atenção Básica } & Apoio institucional \\
\hline & & Educação permanente \\
\hline & & Gestão do monitoramento e avaliação-M\&A \\
\hline & \multirow{2}{*}{ Unidade Básica de Saúde } & Infraestrutura e equipamentos \\
\hline & & Insumos, imunobiológicos e medicamentos \\
\hline \multirow{4}{*}{ Equipes } & \multirow{4}{*}{$\begin{array}{l}\text { Perfil, Processo de } \\
\text { Trabalho e Atenção à } \\
\text { Saúde }\end{array}$} & Perfil da equipe \\
\hline & & Organização do processo de trabalho \\
\hline & & Atenção integral à saúde \\
\hline & & Participação, controle social e satisfação do usuário \\
\hline
\end{tabular}

Fonte: Programa Nacional de Melhoria de Acesso e Qualidade de Atenção Básica

Quadro 2.5 - Instrumento Autoavaliação para Melhoria do Acesso e Qualidade da Atenção Básica

\subsubsection{Monitoramento}

O monitoramento dos indicadores contratualizados é uma ferramenta essencial para a implantação e monitoramento do programa, tanto para a EAB quanto pela gestão municipal, permitindo a identificação de desafios, analise dos resultados, e a efetividade ou necessidade de mudanças de estratégias de intervenção. Também visa 
dar transparência a gestão da $A B$, fortalecendo a participação do usuário por meio de publicação das metas, padrões de qualidade resultados alcançados (Pinto et al.).

O monitoramento dos indicadores busca (Brasil, 2012a):

I - Orientar o processo de negociação e contratualização de metas e compromissos entre as EAB e o gestor municipal, assim como entre este e as outras esferas de gestão do SUS;

II - Subsidiar a definição de prioridades e programação de ações para melhoria da qualidade da $A B$, tanto para as equipes participantes quanto para os gestores das três esferas de governo;

III - Promover o aprendizado institucional ao permitir a identificação e priorização de desafios para a melhoria da qualidade da $A B$, 0 reconhecimento dos resultados alcançados e a efetividade ou necessidade de aperfeiçoamento das estratégias de intervenção;

IV - Promover a democratização e transparência da gestão da $A B$ e 0 fortalecimento da participação do usuário, por meio da publicização de metas, padrões de qualidade e resultados alcançados; e

$\mathrm{V}$ - Fortalecer a responsabilidade sanitária e o protagonismo dos diversos atores ao revelar tanto as fragilidades quanto os sucessos, motivando as equipes de saúde e gestores da $A B$ para enfrentarem os desafios.

No que se referem aos processos locais de monitoramento da $A B$, alguns pressupostos podem ser úteis para orientar o seu desenho, implantação e aperfeiçoamento. Entre eles, podemos destacar:

I - Ter caráter formativo, pedagógico e reorientador das práticas, numa abordagem em que a informação possa produzir mudança na ação. $O$ processo de monitoramento não deve ser entendido como um fim em si mesmo ou apenas como cumprimento de um compromisso meramente formal, mas sim como mecanismo capaz de produzir a mudança, gerando propostas para a melhoria da qualidade das ações e processos monitorados, além de promover aprendizado institucional e responsabilização;

II - Subsidiar a gestão da AB, incorporando informações sobre desempenho aos processos decisórios e alinhando os processos de monitoramento, planejamento, educação permanente e apoio institucional;

III - Evitar a vinculação dos processos de monitoramento a consequências punitivas que reforcem resistências, deturpação de resultados ou tensões desnecessárias que dificultem a apropriação de seus resultados e comprometam o interesse e motivação dos profissionais em alimentar adequadamente os sistemas informação;

IV - Reconhecer o sucesso das equipes que tiverem bom desempenho, estimulando-as na busca de melhores resultados;

V - Permitir a identificação de experiências exitosas e a criação de oportunidades de cooperação horizontal entre as equipes, promovendo 0 
reconhecimento entre pares e relações solidárias, mais do que a competição por melhores resultados;

VI - Possuir mecanismos que assegurem a participação democrática dos envolvidos, constituindo um processo de negociação e pactuação entre sujeitos que compartilham corresponsabilidades;

VII - Estabelecer mecanismos de divulgação sistemática dos resultados do processo de monitoramento da $A B$, com vistas à democratização e transparência desses processos, ao aprendizado institucional, ao reconhecimento dos resultados alcançados e ao enfrentamento dos desafios para melhoria da qualidade da $A B$.

\subsubsection{Educação Permanente}

A Educação Permanente (EP) é um importante investimento aos trabalhadores, gestores e usuários, para que tenham maior capacidade de intervenção e autonomia para contribuir nas práticas transformadoras do modelo de atenção sugerido pelo PMAQ-AB. Deve contemplar a aquisição e atualização dos conhecimentos e habilidades, até os problemas e desafios enfrentados no processo de trabalho que façam sentido para os atores envolvidos (Brasil 2012d, c; Pinto et al., 2012).

O planejamento da EP deve ser realizado a partir da análise coletiva, onde são identificados os nós críticos, passando para uma programação educativa ascendente visando à elaboração de estratégias de atuação dos sujeitos envolvidos (Brasil 2012c).

A presença do apoio institucional nos processos da EP poderia aumentar as alternativas para o enfrentamento das dificuldades vivenciadas pelos trabalhadores conforme propõe o PMAQ-AB. Sugere que o apoio institucional seja pensado como uma função gerencial que busca a reformulação do modo tradicional de se fazer gestão em saúde (Brasil 2012 d, b; Pinto, 2012; Pinto et al., 2012) 


\subsubsection{Apoio Institucional}

O PMAQ-AB muda a forma de pensar do apoio institucional tradicional, municipal, estadual e federal, que prioriza a checagem e prescrição de normas, monitorando a disciplina e no enquadramento das ações. Direciona a gestão junto às equipes em auxiliar na análise das ações, e a construção de intervenção nos resultados. O apoio institucional deixa de reprimir as ações das $E A B$, passando em apoiar a identificação dos problemas do cotidiano e auxiliando na identificação das possíveis soluções, onde pode participar efetivamente na execução da estratégia proposta pelo coletivo, ou apenas como um facilitador na construção. (Brasil 2011, 2012d, 2012c; Pinto et al.).

Segundo Pinto et al., a atenção e gestão devem construir pactos e ações embasados na avaliação, planejamento, educação permanente, gestão do trabalho, qualificação do processo do trabalho e monitoramento de resultados, como forma de mudar o modelo de ação praticado tradicionalmente.

Brasil (2012d) cita alguns exemplos de ações que podem ser realizadas pelos apoiadores:

I - Discussão e montagem das agendas das equipes enquanto dispositivos que organizam e orientam o trabalho coletivo cotidiano em função das necessidades e prioridades de saúde;

II - Suporte à implantação do acolhimento à demanda espontânea

III - Suporte à construção de projetos terapêuticos singulares, a partir de casos ou situações que mobilizam ou desafiam a equipe;

IV - Suporte à implantação de dispositivos para qualificação da clínica, gestão do cuidado e regulação de recursos da rede a partir da equipe da UBS;

V - Facilitação da organização de intervenções intersetoriais;

VI - Análise de indicadores e informações em saúde;

VII - Facilitação dos processos locais de planejamento;

VIII - Mediação de conflitos, buscando ajudar na conformação de projetos comuns entre trabalhadores, gestores e usuários, sem pretender eliminar diferenças e tensões, mas buscando enriquecer os processos com o convívio das diferenças, o esforço de escuta/diálogo, a conversão das crises paralisantes em crises produtivas e a construção de projetos comuns;

IX - Articulação de ações de apoio matricial junto aos NASF e a outros serviços da rede. 


\subsubsection{Avaliação Externa}

A terceira fase (avaliação externa): será a fase em que se realizará um conjunto de ações que averiguará as condições de acesso e da qualidade da totalidade dos municípios e Equipes da Atenção Básica que participam do programa, também busca reconhecer e valorizar os esforços e os resultados das $E A B$ e dos gestores municipais de saúde no processo do PMAQ-AB. O processo é conduzido por instituições de ensino e/ou pesquisa contratadas pelo Ministério da Saúde Brasil (Brasil, 2011; Brasil 2012a,b; Pereira et al., 2013; Pinto, 2012; Barros, 2013; Barroso et al., 2013).

O processo de avaliação externa também possibilita: reforçar práticas de cuidado, gestão e educação que contribuam para a melhoria permanente da atenção básica à saúde ofertada ao cidadão; fortalecer ações e estratégias das gestões do SUS que qualifiquem as condições e relações de trabalho e que busquem apoiar tanto o desenvolvimento do processo de trabalho das equipes quanto dos próprios trabalhadores; subsidiar a recontratualização das equipes de forma singularizada, respeitando suas potencialidades e dificuldades; considerar a avaliação dos usuários e fortalecer sua participação no esforço de qualificação permanente do SUS; conhecer em escala e profundidade, inédita, as realidades e singularidades da atenção básica no Brasil, registrando as fragilidades e potencialidades de cada lugar contribuindo para planejamento e construções de ações de melhoria em todos os níveis; elaborar estratégias adequadas às diferenças dos territórios, promovendo maior equidade nos investimentos dos governos federal, estadual e municipal (Brasil, 2012b).

Essa fase é dividida em duas dimensões (Brasil, 2011; 2012d, b; Barros 2013):

Certificação de desempenho das equipes de atenção básica e gestões municipais participantes do PMAQ-AB: avaliação do acesso e da qualidade das EAB participantes do PMAQ-AB, por meio do monitoramento dos indicadores contratualizados e pela verificação de um conjunto de padrões de qualidade no próprio local de atuação das equipes;

Avaliação do acesso e da qualidade da atenção básica não relacionada ao processo de certificação: constituída por um processo avaliativo que contempla a avaliação da rede local de saúde pelas equipes de atenção básica e processos complementares de avaliação da satisfação do usuário e da utilização dos serviços. 
É o momento onde ocorre a certificação das equipes da atenção básica, reconhecendo o esforço da melhoria do acesso e qualidade das $E A B$ e o gestor Municipal, estimulando o desenvolvimento de ações para a melhoria da qualidade. $O$ processo da avaliação externa constituirá na aplicação de um instrumento composto pelos padrões da qualidade no próprio local de atuação das EAB. O instrumento de avaliação externa será organizado em quatro grandes dimensões e 12 subdimensões, que consistem nos eixos de análise orientadores dos padrões de qualidade (Brasil, 2012d,b e Brasil, 2013b,c,d).

Segundo Brasil (2012d) Critérios para a certificação são: Implementação dos processos avaliativos ( $10 \%$ da nota final), verificação do desempenho alcançado para o conjunto de indicadores contratualizados ( $20 \%$ da nota final) e, verificação de evidências para um conjunto de padrões de qualidade ( $70 \%$ da nota final).

A partir da avaliação externa, as equipes da atenção básicas poderão ser classificadas em quatro categorias (Brasil 2012d);

I - Desempenho insatisfatório: quando o resultado alcançado for menor do que -1 (menos um) desvio-padrão da média do desempenho das equipes contratualizadas em seu estrato;

II - Desempenho regular: quando o resultado alcançado for menor do que a média e maior ou igual a -1 (menos um) desvio-padrão da média do desempenho das equipes em seu estrato;

III - Desempenho bom: quando o resultado alcançado for maior do que a média e menor ou igual a +1 (mais um) desvio-padrão da média do desempenho das equipes em seu estrato; $e$

IV - Desempenho ótimo: quando o resultado alcançado for maior do que +1 (mais 1) desvio-padrão da média do desempenho das equipes em seu estrato.

No segundo ciclo de certificação, as equipes serão comparadas entre elas, mas também em relação ao seu desempenho alcançado (Brasil, 2012a).

Uma vez que a EAB seja certificada o gestor municipal passara a receber valores diferenciados do $P A B$ variável:

- Regular: $20 \%$ do componente do PAB Variável

- Boa: $60 \%$ do componente do PAB Variável

- Ótima: $100 \%$ do componente do PAB variável. 
Vale pontuar que, para garantir a equidade na comparação das $E A B$, os municípios serão distribuídos em estratos, que levam em conta os aspectos sociais, econômicos e demográficos (Brasil 2012a).

\subsubsection{Recontratualização}

A quarta fase (recontratualização): a partir da avaliação dos resultados alcançados pela as equipes da $A B$ e o município, ocorre à nova pactuação com incrementos de novos padrões e indicadores de qualidade.

Recentemente o CEO passou a fazer parte do PMAQ, denominado Programa nacional de melhoria do acesso e qualidade dos centros de especialidades odontológicas (PMAQ-CEO), instituído através da Portaria no 261/GM/MS, de 21 de fevereiro de 2013. Realizado nos mesmos moldes do PMAQ-AB, tem como objetivo avaliar o desempenho do CEO, e irá repassar mais recursos para os serviços que cumprirem com os padrões de qualidade pactuados (Brasil, 2013a).

Da mesma forma que o PMAQ-AB, o MS estimula a participação dos municípios no programa, repassando, fundo a fundo, recursos financeiros para cada CEO participante. Para o acompanhamento dos CEOs no programa, também é utilizado o dados que estão no SIAB, divididos em: indicadores de desempenho e monitoramento (Brasil, 2013a).

1. Indicadores de desenpenho:

- Procedimentos básicos realizados em pessoas com necessidades especiais no mês

- Procedimentos de periodontia no mês

- Procedimentos de endodontia no mês

- Procedimentos de cirurgia oral no mês

- Procedimentos de endodontia em dentes permanentes com 3 ou mais raízes no mês

- Procedimentos restauradores realizados em pessoas com necessidades especiais no mês 
2. Indicador de Monitoramento

- Proporção de exodontias em relação aos procedimentos clínicos odontológicos individuais em pessoas com necessidades especiais

Também é importante citar a inclusão do Núcleo de Atenção à Saúde da Família no PMQ, através das portarias: Portarias № 3.124 de 28 de dezembro de 2012 e a Portaria № 2.488 de 21 de outubro de 2011 (2012a). 


\section{PROPOSIÇÃO}

Avaliar 0 potencial de contribuição do processo PMAQ-AB para 0 fortalecimento e consolidação da PNSB no âmbito do SUS. 


\section{METODOLOGIA}

Este trabalho foi realizado com base em uma revisão de literatura descritiva, que envolveu as fases de busca, análise e interpretação de artigos, periódicos, livros texto e materiais institucionais, além de leis e portarias de interesse para o estudo.

Para fase de busca bibliográfica, foram utilizadas as seguintes palavras-chave: Sistema Único de Saúde, Avaliação, gestão, saúde, Odontologia. O período analisado foi entre 2001 e 2013. Os bancos de dados consultados foram Scielo, Google Acadêmico e Biblioteca Virtual de Saúde.

Para fase de análise, todos os resumos e abstracts foram lidos, assim como os títulos dos trabalhos, e identificados os potenciais de contribuição de cada trabalho para resposta da pergunta de pesquisa. Selecionados os artigos e trabalhos a serem interpretados, esses últimos foram lidos na íntegra e categorizados segundo interesse dos autores para condução do trabalho.

Após fase de organização e redação da revisão da literatura, foi descrita a discussão e as conclusões, com base na proposição do estudo. 


\section{DISCUSSÃo}

Quando se observa a história das políticas públicas de saúde no Brasil, desde a época do Brasil colônia, observamos que esta história sempre esteve e está vinculada, por um lado, ao contexto político-econômico e social de nosso país e por outro lado, ao contexto socioeconômico mundial. Além dessas variáveis, influenciou a história das políticas públicas de saúde no Brasil o próprio conceito de saúde, que ao longo dos tempos foi sendo alterado.

No Brasil, o continente que mais influenciou as profissões médicas certamente foi a Europa, se levarmos em conta a idade moderna ou industrial não podemos nos esquecer da revolução industrial, que com o avanço selvagem do capitalismo e consequente deterioração das relações de trabalho, e aumento dos agravos relacionados às péssimas condições de trabalho, fez surgir um importante movimento denominado de Medicina Social, que mais tarde fora calado pelo modelo unicausal da doença, com base na descoberta da bactéria, sobretudo, por Pasteur em 1896. O final do século XIX e o início do século XX foram marcados pela teoria unicausal da doença, em que apenas o aspecto biológico do adoecimento era levado em consideração no tratamento da doença.

Outro aspecto importante destacado no texto e que explica como as políticas públicas no Brasil se desenvolveram foi a grande influência mais recente exercida pelo modelo norte-americano, pois o modelo de ensino de medicina, centrado no biologissismo, na unicausalidade das doenças, excessivamente hospitalocêntrico e fragmentado chegou até o Brasil através da forte influência e do poder econômico da Rockfeller Foundation, retrato do poder capitalista sobre a saúde nos Estados Unidos, modelo que observamos até hoje no ensino em saúde no Brasil.

Diante do exposto, foi escrito sobre a evolução das políticas públicas no Brasil a partir de meados do século $X X$, já que entende-se que este foi um período determinante para o sistema de saúde no Brasil que se estabelece nos dias de hoje.

Foi observado que durante meados do século XX o Brasil viveu um modelo de assistência pública à saúde que vinculava o direito à assistência apenas ao setor produtivo da população, ou seja, apenas àqueles que contribuíam de alguma forma 
com a previdência social ou com as organizações por categoria de trabalho (CAPS e IAPS).

O modelo de atenção excludente citado acima foi sendo paulatinamente questionado pelos movimentos sociais no Brasil, que em plena época de ditadura militar, discutiam mais direitos civis à população com mais seguridade social, e certamente a saúde foi incluída como tema principal de suas reinvindicações.

Esta foi uma construção social que por décadas foi sendo realizada, especialmente por uma elite intelectual que lutava contra a ditadura e por mais direitos sociais. Vale lembrar que na década de 70 as conferências de promoção de saúde, especialmente Alma Ata, influenciaram sobremaneira estes movimentos.

Os anos seguintes foram caracterizados por lutas, perseguições políticas, com servidores públicos demitidos e presos. Observamos também que foi neste período que ocorreram as $5^{\underline{a}}, 6^{\underline{a}}$ e $7^{\underline{a}}$ Conferências Nacionais de Saúde, além da criação da ABRASCO em 1979. Como foi ressaltado ficava claro que o movimento se fortalecia e o debate sobre a saúde pública e sobre a democracia já era uma realidade.

De todas as Conferências do período pré -democracia, a VIII Conferência de saúde (1986), foi a mais importante, pois nela foram desenhados os princípios do futuro sistema nacional de saúde, que deveria ser universal, integral, equânime, com participação popular, descentralizado e hierarquizado. Foi um modelo que corrigia desigualdades e que deveria incluir no sistema público de saúde milhões de brasileiros "indigentes" para o então sistema vinculado ao INPS e mais tarde ao INAMPS.

Já na história mais recente das políticas públicas no Brasil, ficou evidenciado que em 1988, com a promulgação da Constituição Brasileira, foi institucionalizado o denominado Sistema Único de Saúde (SUS), nos moldes descritos na VIII Conferência Nacional de Saúde.

Estudando a história das políticas públicas de saúde no Brasil não se pode negar que ela foi se alterando ao longo dos anos, influenciada sobremaneira por interesses econômicos, políticos e sociais, que interna e externamente foram moldando a saúde pública em nosso país. Após 1988, o SUS que até hoje se mantém com o mesmo nome, entretanto ele foi sendo reinventado e transformado, à medida que ia amadurecendo como política de Estado.

Observou-se que após quase 25 anos de sua institucionalização, à despeito de ter permanecido com o mesmo "nome fantasia", o SUS se transformou, se reinventou 
por vezes e se tornou uma política de Estado consolidada e uma conquista da população brasileira.

Para finalizar o capítulo de história da políticas públicas de saúde no Brasil, vale ressaltar que o motivo pelo qual foi estudado o passado é porque com lições aprendidas pode seguir adiante e acertar mais do que errar. Estudar a evolução das políticas públicas de saúde no Brasil é constatar que o contexto sócio-políticoeconômico de cada época, seja no campo nacional, seja no campo internacional, influenciou sobremaneira o modo como a saúde era vista em sua época e como os sistemas de saúde foram organizados e foram se transformando ao longo do tempo. Somos resultado desta história e agora estamos escrevendo um novo capítulo deste livro, no qual o SUS é ator principal há 25 anos.

Neste período de consolidação e fortalecimento do SUS, foi destacado no texto o percurso da saúde bucal neste contexto. Foi observado que a história das políticas e programa de saúde bucal no interior do SUS foram desenhadas e percorridas de forma singular e nem sempre alinhadas aos princípios do próprio SUS.

No texto, ficou claro que, em paralelo, a Saúde Bucal Coletiva também escreveu sua história. Deve-se lembrar que o Brasil viveu, na instalação e nos primeiros anos do SUS, a realidade do neoliberalismo e sua teoria do "Estado mínimo", com isso, foram muitos os obstáculos que a Saúde Bucal Coletiva, enfrentou para se estabelecer e expandir seu alcance, dando voz aos ideias por ela proclamados e estabelecidos, dentre outros movimentos, pelas $1^{\text {a }}$ e $2^{\text {a }}$ Conferências Nacionais de Saúde Bucal.

Ficou claro que alguns ensaios de políticas e programas foram desenvolvidos nos primeiros anos de SUS, todos com pequeno financiamento e ideias curativistas e reducionistas, ao contrário do que pregava a Constituição. O programa nacional de controle da cárie dental e com uso de selantes e flúor (PNCCSF) e o PRECAD (Programa Nacional de Prevenção da Cárie Dental), lançados pelo INAMPS e instintos pelo governo Collor 2 anos depois, baseavam-se na verticalização das ações, de forma centralizadora e autoritária, sendo absolutamente opostos ao que rezava a Constituição (Frazão e Narvai 2009a,b).

A história da saúde bucal coletiva em nosso país engatinhou muito lentamente na prática, por um lado, mas intensamente e vigorosamente do ponto de vista teórico, pois a academia, pesquisadores e intelectuais da época fizeram surgir uma intensa produção intelectual que mais tarde serviria de suporte à atual Política Nacional de 
Saúde Bucal (PNSB) em vigor no Brasil desde 2004. Na visita feita à história da saúde bucal coletiva no Brasil, que a PNSB estabelecida em 2004 foi fruto das discussões e apontamentos, sobretudo, da III CNSB, que por sua vez foi um acúmulo de discussões que por décadas foram realizadas pela categoria de profissionais da saúde bucal coletiva no Brasil.

Observa-se que apenas no governo Lula a saúde bucal foi declarada área estratégica e a Coordenação Nacional de Saúde Bucal recebeu apoio político e aporte financeiro para tirar do campo da teoria as aspirações da Saúde Bucal Coletiva no Brasil e de seus intelectuais e pesquisadores. Pucca em 2006 afirmou que a PNSB é uma conquista social e uma resposta aos anseios da saúde bucal coletiva e seus idealizadores, à medida que ela responde aos anseios por décadas descritos por militantes da área.

$\mathrm{Na}$ revisão foi observado que a PNSB está alinhada às diretrizes e pressupostos do SUS e se constitui em uma complexa política que contempla os níveis de atenção organizados em redes integrais e poliárquicas, tendo a atenção básica como a responsável pela organização do sistema, com base na Estratégia de Saúde da Família, além da organização do cuidado por ciclo de vida (Brasil, 2006).

Foi utilizada como estratégia de expansão da saúde bucal no SUS o incremento de equipes de saúde bucal (ESB) na ESF, para a melhoria no acesso e viabilização e estabelecimento da rede poliárquica citada anteriormente. Ficou claro que o número de ESB saltou de 4261 em 2002 para 22.139 em 2012. Também observa-se que além de aumentar o número de ESB, buscou-se distribui-las de forma mais justa pelo território nacional. Em 2012 os registros do MS indicavam que 4907 cidades possuíam pelo menos 1 ESB, este número era de apenas 2.302 em 2002. Como consequência deste incremento no número absoluto e no número relativo de ESB pelos municípios, a cobertura cresceu de 7\% em 2002 para 39\% em 2012.

Outro aspecto ressaltado foi a criação dos Centros de Especialidades Odontológica (CEO), já que a atenção especializada é um importante gargalo na atenção à saúde e não só na saúde bucal no Brasil. A criação de uma rede estruturada de atenção secundária foi tão importante para a saúde bucal no contexto do SUS, que apesar de nos parecer um erro, os CEOS se tornaram quase que sinônimo da PNSB.

Ainda na média complexidade, pode-se perceber que um importante passo dado pela PNSB foi a criação dos Laboratórios Regionais de Prótese Dentária (LRPD), à medida que a Odontologia mutiladora desempenhada por décadas em nosso país 
resultou em uma população adulta e idosa desdentada (parcial ou total) que necessita ser reabilitada, já que $70 \%$ dos idosos no Brasil são desdentados e na faixa etária de 30 a 44 anos, 30 \% dos adultos não tem um dente na boca. Com base em registros e documentos oficiais da PNSB, observamos que atualmente contamos com cerca de 1380 laboratórios, que necessitam de um investimento de mais de 8 MILHOES/MÊS.

Ainda na direção de estruturar a rede de atenção em saúde bucal, a alta complexidade em Odontologia também foi contemplada na PNSB, entretanto de forma mais tímida, já que estamos tratando de uma área em que a saúde bucal faz interface com a Medicina e resoluções e encaminhamentos devem contemplar os interesses de áreas, que por vezes entram em conflitos. Foi destacado como importantes conquistas para saúde bucal o credenciamento de Centro de Alta Complexidade em Oncologia (Cacons) e a Unidade de Alta Complexidade em oncologia (Unacons), vinculado à presença do dentista na equipe. Isso garante que os pacientes oncológicos tenham acesso à atenção odontológica antes, durante e depois de seu tratamento, também outra conquista, à medida que atualmente o Cirurgião Dentista (CD) pode internar pacientes, o que não era possível legalmente no passado. Por fim, observou-se que está na agenda do MS a ampliação dos atendimentos de pacientes com necessidades especiais, sob sedação e anestesia geral, além de outros elementos da Odontologia Hospitalar, que devem ser enfrentados e implementados no futuro próximo.

Foi observado que os elementos básicos do modelo de atenção à SB proposto em 2004 são a APS, CEOS e Alta Complexidade, entretanto muitos outros atores e práticas são parte integrante deste processo. Deve-se lembrar que no modelo estão previstas atividades extra-clínicas, tais como as visitas domiciliares, levantamentos de necessidades, com referenciamentos de pacientes aos demais níveis, atendimentos e assistência domiciliar, atividades de educação em saúde.

Não se pode negar que os últimos 10 anos foram, de ouro para saúde bucal coletiva e para saúde bucal no interior do SUS, apesar de haver uma longa estrada a ser percorrida, hoje a saúde bucal é área estratégica da atenção básica e do próprio sistema nacional de saúde, entretanto a política nacional de saúde bucal apresenta uma fragilidade que ainda não se tem dimensão de como poderia ser equacionada, à saber, a troca e alternância democrática do poder pela administração federal, especialmente. Desde 2002 o Brasil é governando pelo Partido dos Trabalhadores e, portanto, mesmo enfrentando muitos ajustes de políticas, trocas frequentes de 
ministros da saúde e a própria eleição da presidenta Dilma Rousseff, a PNSB não enfrentou uma troca de governo, com outro partido no poder. Será que sob a lógica neoliberal o Brasil Sorridente sobreviverá? Ou em um governo de extrema direita, a saúde bucal ainda seria área estratégica? Percebe-se que só quando a PNSB passar do status de política de governo para política de Estado é que ela resistirá às intemperies dos governos e suas trocas no poder e em no texto foi explorado um pouco algumas possíveis estratégias para fortalecimento da PNSB.

As histórias citadas acima e retomadas na revisão de literatura revela uma singularidade que se confunde com a própria história de nosso país, entretanto fica evidente na revisão da literatura que esta não é uma história acabada, muito pelo contrário, ela é revisitada, revisada, reescrita, reinventada a todo momento e um bom exemplo deste reinventar de práticas e de saberes é o Programa de Saúde da Família (PSF), hoje denominado Estratégia de Saúde da Família (ESF).

Foi observado que o PSF, criado em 1994, é uma estratégia para reorganização da $A B$ do modelo tradicional, que tem como enfoque as ações de promoção da saúde, prevenção dos agravos e recuperação da população com enfoque das famílias, observadas em seu contesto sócio econômico e cultural (Programa de Saúde da Família Saúde Bucal, 2006). Foi visto que só no ano de 2000 houve a inclusão da Saúde Bucal (SB), com o intuito de ampliar o acesso às ações de saúde no conjunto das atividades desenvolvidas pela ESF (Munkeviz e Pelicione, 2010). Também foi citado que ao longo das diversas estratégias de gerenciamento de um sistema universal disponibilizado para mais de 200.000.000 de habitantes, buscou-se modelos inovadores de gestão, tais como parcerias com fundações e organizações sociais, além da administração pública direta (Alcântara, 2011).

Foi destacado na revisão da literatura que a gestão tem sido uma importante estratégia para viabilizar o SUS sua expansão e consolidação. Foi observada que uma importante aliada da gestão é a avaliação e concluído que vivemos atualmente no interior do SUS um intenso processo de avaliação de práticas, serviços e políticas. Também foi observado que a avaliação auxilia na melhoria da capacidade de tomada de decisão por parte do gestor, que necessita ser aplicada constantemente durante os processos, programas e prestação de serviço (Tanaka, Tamaki, 2012). Também foi discutido que o processo de avaliação no setor público não é simples, à medida que os profissionais de saúde não se sentem confortáveis aos serem avaliados e os 
gestores, que via de regra também são profissionais da saúde, parecem ter dificuldade para desenvolver os processos de avaliação de forma adequada.

Foi neste contexto que o MS implantou o PMAQ-AB com o objetivo de estimular a ampliação da capacidade das gestões federal, estaduais e municipais, além das Equipes de Atenção Básica $(E A B)$ e, em ofertar os serviços de acordo com as necessidades concretas da população. Visa induzir a ampliação do acesso da Atenção Básica, com garantia de um padrão de qualidade, bem como permitir maior transparência e efetividade das ações governamentais direcionadas à Atenção Básica de Saúde.

$\mathrm{Na}$ literatura percebeu-se que o PMAQ-AB trouxe mudanças significativas ao vincular repasses de recursos à implantação e obtenção dos padrões de qualidade alcançados pela $E A B$, além de condicionar seu sucesso à capacidade de mobilizar os atores locais visando mudanças das condições e práticas de atenção, gestão e participação orientadas por diretrizes pactuadas nacionalmente. A qualidade deste programa favorece a criação de espaços de discussão entre equipes, gestores e usuários com o objetivo de produzir mudanças concretas na realidade cotidiana, onde a referência dos sujeitos envolvidos varia de acordo com o seu contexto histórico, político, econômico, tecnológico e cultural e com o conhecimento acumulado durante a sua existência. O PMAQ, dividido em quatro fases, traz diferentes movimentos no processo da busca da qualidade da $A B$.

Na primeira fase, denominada adesão e contratualização, já traz um importante impacto para os profissionais de saúde, tendo em vista que não existe a obrigatoriedade para a participação do programa. $O$ fato de ser voluntária a adesão, obriga gestores, trabalhadores e usuários a terem um ambiente de diálogo e objetivos comuns, já que aderir ao programa exige uma série de compromissos compartilhados que necessitam ser pactuados entre todos os atores do processo. Outro ponto importante que foi observado na revisão da literatura é quando este processo ocorre conjuntamente com Município e EAB, criando um vínculo de responsabilidades e objetivos comuns entre estes atores que já podem ser percebidos quando os compromissos são firmados (Pinto, 2013).

Deve-se ressaltar que é mandatório que a $E A B$ assine o compromisso de seguir diretrizes organizantes do processo de trabalho, o que inclui uma série de pressupostos tais como: observar regras de funcionamento do programa; implantar dispositivos de acesso, cogestão, auto avaliação, planejamento e avaliação 
relacionados a cada uma das fases posteriores; ser monitorada por seis meses a partir de quarenta e sete indicadores do Sistema de Informação da Atenção Básica (SIAB); passar por um processo de avaliação que inclui a autoavaliação, o desempenho em vinte e quatro indicadores. A revisão da literatura também mostrou que no momento da contratualização a equipe aceita se submeter a uma avaliação in loco realizada por avaliadores externos que visitam cada equipe na terceira fase do programa (Pinto, 2013). Neste momento é oportuno citar a inclusão de sete indicadores de saúde bucal, quatro de desempenho e três de monitoramento, estimulando a transformação das práticas atuais de saúde bucal, com vistas à melhoria no acesso ao atendimento de qualidade, e qualificando as ação da PNSB. Seguem os indicadores propostos:

Indicadores de desempenho:

- Média da ação coletiva de escovação dental supervisionada

- Cobertura de primeira consulta odontológica programática

- Cobertura de primeira consulta de atendimento odontológico à gestante

- Razão entre tratamentos concluídos e primeiras consultas dontológicas programáticas.

Indicadores de monitoramento:

- Média de instalações de próteses dentárias

- Média de atendimentos de urgência odontológica por habitante

- Taxa de incidência de alterações da mucosa oral.

Ressaltamos na revisão de literatura que a escassez de trabalhos sobre 0 PMAQ e, especialmente sobre a inserção da saúde bucal neste processo, dificulta por um lado a discussão, mas traz um ineditismo a este texto, que pela primeira vez vinculou a contribuição do PMAQ no processo de amadurecimento, fortalecimento e consolidação da PNSB. Inserir indicadores de desempendo e de monitoramento de saúde Bucal no maior processo de avaliação da história do Sistema Único de Saúde certamente reforça a ideia de setor estratégico que a saúde bucal ocupa no contexto da atenção básica e garante a possibilidade de que a PNSB seja avaliada e possa, ao 
observar seus indicadores, tomar decisões, implementando mudanças, corrigindo erros e identificando acertos.

Tendo assinado o termo de adesão por toda a $E A B$, o Município incluiu o cadastramento das EAB com a aplicação dos recursos do Componente de Qualidade do PAB Variável, o que implica numa série de atos a serem realizados, a saber: realização de ações para a melhoria das condições de trabalho das EAB, estruturação da gestão da $A B$ garantindo condições de funcionamento da equipe de gestão responsável pela implantação local do Programa, e envolvendo a mesma no apoio institucional às EAB para realização da auto avaliação, instituição de mecanismos de gestão colegiada nas UBS e de avaliação e monitoramento de indicadores, desenvolvimento de ações de educação permanente e execução de ações compartilhadas de superação dos problemas identificados para o alcance dos resultados pactuados (Pinto, 2013).

A segunda etapa, denominada de desenvolvimento, é a responsável pelas ações realizadas fundamentalmente pelas EAB e gestão municipal, apoiada pelas gestões estaduais e Ministério da Saúde. Esta é dividida em quatro partes: auto avaliação, monitoramento, educação permanente e apoio institucional e a literatura aponta que esta é uma fase fundamental para o sucesso do processo, já que pressupõe ações advindas da EAB e com a participação direta e ativa da gestão municipal.

A auto avaliação, propõe o desenvolvimento de um processo de identificação de dimensões positivas e problemáticas do trabalho, facilitando, novamente, mais um espaço de discussão e cogestão das EAB. Vale ressaltar que a literatura aponta como ganho para esta fase de avaliação, o fato do MS ter implementado mudanças importantes no SIAB, que facilitaram a avaliação, acompanhamento e planejamento das ações por parte do colegiado da $A B$.

Também ficou explícito na revisão, que é fundamental a educação permanente estar inserida no PMAQ-AB, pois se existe a pretensão de qualificar os serviços de saúde e os profissionais, com mudanças nos processos de trabalho, os sujeitos necessitam ter maior capacidade de intervenção e autonomia para que as mudanças ocorram. O programa sugere a articulação do apoio institucional (Al), visando aumentar a capacidade dos enfrentamentos das dificuldades dos profissionais, firmando novamente, a articulação das equipes e gestão. O Al deve dar suporte ao movimento de mudança deflagrado pelo coletivo. 
A terceira fase, avaliação externa, é o momento do levantamento das informações para análise das condições do acesso e da qualidade, e o reconhecimento dos resultados dos esforços das $E A B$ e dos gestores municipais na qualificação da $A B$, dando retorno aos sujeitos, e estimulando e provocando o coletivo em agir pela mudança do cotidiano.

A quarta fase, recontratualização, é a fase para 0 reinicio das contratualizações, que estão ocorrendo atualmente pela primeira vez e, portanto, ainda não possui na literatura nenhum registro sobre sua evolução.

Mais recentemente o CEO passou a fazer parte do PMAQ, denominado Programa nacional de melhoria do acesso e qualidade dos centros de especialidades odontológicas (PMAQ-CEO), instituído através da Portaria no 261/GM/MS, de 21 de fevereiro de 2013. Tal fato evidencia o comprometimento e desenvolvimento do Governo Federal, nas ações voltadas para a melhoria do acesso e qualidade no SUS. Também é inédita a inclusão de um serviço secundário no programa, sugerindo a preocupação em dar acesso e qualidade em todos os níveis de atenção à saúde

Outro exemplo importante que aponta para a ampliação do PMAQ-AB é a inclusão os Núcleos de Apoio à Saúde da Família (NASF) através da Portaria GM/MS ํo 261, de 21 de fevereiro de 2013.

Portanto, percebeu-se indícios de que ao ser incluída no PMAQ, a saúde bucal se fortalece e se consolida, sendo possível que um dia a PNSB se torne uma política de Estado e não apenas de uma governo ou de um partido político. 


\section{CONSIDERAÇÕES FINAIS}

Esta revisão permitiu, uma visita à história das políticas públicas de saúde no Brasil, identificando que o atual "status" do SUS é resultado de uma longa e singular história, que contou a contribuição de muitos atores e sujeitos que ao longo dos anos foram escrevendo seus parágrafos e palavras nesta história. Também percebeu-se que temos privilégio de viver a história do SUS nos dias atuais, já que ele se transforma e se reinventa para alcançar os enormes desafios a ele impostos na Constituição de 1988. Foi visto que em paralelo à história do SUS, a saúde bucal coletiva e seus idealizadores, a quem deve-se muito, escreveram e produziram intensa produção intelectual que em 2004 culminaram com a criação da Política Nacional de Saúde Bucal, denominada de "Brasil Sorridente". Observou-se que antes da PNSB, a saúde bucal e seus ensaios de políticas foram descolados dos princípios doutrinários e organizacionais do SUS e sem financiamento adequado ou apoio político, fracassaram ou foram pouco eficazes.

Foi possível concluir, com base na literatura, que a PNSB foi a mais adequada e mais alinhada aos princípios do SUS que o Brasil já teve em sua história. Muitos foram os avanços da PNSB nos últimos dez anos, tais como estruturação da rede poliárquica de atenção em saúde bucal, aumento das equipes de saúde bucal na estratégia de saúde da família, criação dos centros de especialidades odontológicas, identificamos atuações importantes na alta complexidade, incentivo para criação de laboratórios de prótese dentária, aumento do acesso à água fluoretada por parte da população brasileira, aumento do controle e da vigilância em saúde bucal, dentre outros. A revisão identificou inúmeros aspectos positivos da PNSB e o fato de que nunca uma política de saúde bucal sobreviveu por tanto tempo, de forma saudável, vigorosa e porque não dizer, pujante. Se por um lado a PNSB é hoje área estratégica do governo e recebe apoio político e financeiro para garantir seu sucesso, foi identificada uma importante fragilidade na mesma, à saber, o fato da PNSB ter sido criada no governo Lula e nunca ter passado por mudanças estruturantes no governo federal, com alternância no poder dos inúmeros partidos que compõem a cena política no Brasil. 
Esta será a maior prova que a PNSB vai ter que se submeter, em um país democrático, é saudável e esperado que os partidos se revezem no poder e cabe à PNSB tornar-se forte o suficiente para aguentar mudanças mais ou menos turbulentas.

Nossa hipótese, exposta neste trabalho, é que quanto mais a saúde bucal estiver embrenhada às políticas e programas estratégicos para o país, mais forte ela se tornará e mais essencial para população e para os governos ela vai ser. Neste contexto, o PMAQ é um excelente exemplo de como a saúde bucal pode se fortalecer, já que este é o maior processo de avaliação pelo qual o SUS está sendo submetido, e ter indicadores de monitoramento e desempenho ligados à saúde bucal no interior do PMAQ é um avanço e uma oportunidade de garantir que a saúde bucal continue a ser valorizada e sustentada em mudanças de governos.

Foi possível observar que o PMAQ é uma realidade, que está se fortalecendo no SUS, já que além do PMAQ-AB, os NASFs e mais recentemente os CEOs estão sendo incluídos neste processo, que parece se concretizar como grande estratégia de avaliação e monitoramento do Sistema Único de Saúde e inserindo indicadores de saúde bucal de monitoramento e avaliação no PMAQ, ao lado de outras estratégias intersetoriais e interministerais, são potencialmente fatores que podem fortalecer e consolidar a PNSB no âmbito do SUS, tornando o Brasil Sorridente uma política de Estado e não a política de um partido político. 


\section{REFERÊNCIAS 1}

Alcântara CM. O público e o privado e os novos modelos de gestão do sistema único de saúde. Bol Saúde. 2011 jan-jun;24(1):21-8.

Araujo ME, Frias AC, Junqueira RJ, organizadores. Odontologia em saúde coletiva: manual do aluno. São Paulo: Faculdade de Odontologia da Universidade de São Paulo; 2007.

Azevedo UN, Costa JW, Lyra IT. PMAQ-AB: uma avaliação por resultados na saúde. In: Anais do $12^{\circ}$ Congresso Brasileiro de Medicina de Família e Comunidade; 20 maio 02 jun 2013; Belém (PA) [citado 28 dez. 2013]. Disponível em < http://www.cmfc.org.br/index.php/brasileiro/article/view/1273>.

Azevedo BRS. Uma análise sobre os modelos de gestão terceirizados: a desconstrução do discurso [citado 10 set. 2012]. [2010?]. Disponível em: http://observasaude.fundap.sp.gov.br/saude2/sus/acervo/OSS1.pdf.

Barros JFB. O processo de avaliação e monitoramento das políticas públicas de saúde: o caso da PNAB [monografia de conclusão de curso]. Brasília: Universidade de Brasília, Faculdade de Ceilândia; 2013.

Barroso RFF, Vieira JR, Ferla AA, Barbosa MG. Programa nacional de melhoria do acesso e qualidade na Atenção Básica PMAQ. In: Anais do 12ํㅡㄹ Congresso Brasileiro de Medicina de Família e Comunidade, 20 maio 02 jun 2013; Belém (PA) [citado 28 dez. 2013]. Disponível em <

http://www.cmfc.org.br/index.php/brasileiro/article/view/1293>.

Botazzo C. Da arte dentária. São Paulo: Hucitec; 2000.

Brasil. Ministério da Saúde. Portaria $\mathrm{n}^{\circ} 261$, de 21 de Fevereiro. Institui, no âmbito da Política Nacional de Saúde Bucal, o Programa de Melhoria do Acesso e Qualidade dos Centros de Especialidades Odontológicas (PMAQ-CEO) e o Incentivo Financeiro (PMAQ-CEO), denominado Componente de Qualidade da Atenção Especializada em Saúde Bucal. Saúde Legis; 2013a [citado 24 dez. 2013]. Disponível em: < http://bvsms.saude.gov.br/bvs/saudelegis/gm/2013/prt0261_21_02_2013.html>. 
Brasil. Ministério da Saúde. Portaria n 493/GM de 10 de março de 2006. Diário Oficial da União, Poder Executivo, Brasília, DF, 13 de março de 2006.

Brasil. Ministério da Saúde. Portaria no 1.654, de 19 de julho de 2011. Institui, no âmbito do Sistema Único de saúde, o Programa Nacional de Melhoria do Acesso e da Qualidade da Atenção Básica (PMAQ-AB) e o Incentivo Financeiro do PMAQ-AB, denominado Componente de Qualidade do Piso de Atenção Básica Variável - PAB Variável. Saúde Legis; 2011 [citado 24 dez. 2013]. Disponível em: <http://bvsms.saude.gov.br/bvs/saudelegis/gm/2011/prt1654_19_07_2011.html>.

Brasil. Ministério da Saúde. Portaria no 3.124, de 28 de dezembro de 2012. Redefine os parâmetros de vinculação dos Núcleos de Apoio à Saúde da Família (NASF). Modalidades 1 e 2 às Equipes Saúde da Família e/ou Equipes de Atenção Básica para populações específicas, cria a Modalidade NASF 3, e dá outras providências.l. Saúde Legis; 2012a [citado 24 dez. 2013]. Disponível em: < http://bvsms.saude.gov.br/bvs/saudelegis/gm../2012/prt3124_28_12_2012.html>.

Brasil. Ministério da Saúde. Programa Nacional de Melhoria do Acesso e da Qualidade da Atenção Básica (PMAQ): Instrumento de avaliação externa para as equipes de Atenção Básica (Saúde Bucal e Equipes de Saúde Bucal Parametrizada). Brasília; 2013b [citado 20 dez. 2013]. Disponível em: http://189.28.128.100/dab/docs/portaldab/documentos/instrumento_ae_sb. Acesso em: 20 de dez. 2013.

Brasil. Ministério da Saúde. Programa Nacional de Melhoria do Acesso e da Qualidade da Atenção Básica (PMAQ): Instrumento de avaliação externa para as equipes de Atenção Básica (Saúde da Família e Equipes Parametrizadas) e NASF. Brasília; 2013c [citado 20 dez. 2013]. Disponível em:

http://189.28.128.100/dab/docs/portaldab/documentos/instrumento_ae_sf. Pdf.

Brasil. Ministério da Saúde. Programa Nacional de Melhoria do Acesso e da Qualidade da Atenção Básica (PMAQ): Manual Instrutivo para as equipes de Atenção Básica (Saúde da Família, Saúde Bucal e Equipes Parametrizadas) e NASF. Brasília; 2013d [citado 20 dez. 2013]. Disponível em: http://189.28.128.100/dab/docs/portaldab/publicacoes/manual_instrutivo_PMAQ_AB 2013.pdf.

Brasil. Ministério da Saúde. Secretaria de Atenção à Saúde. Departamento de Atenção Básica. Autoavaliação para a Melhoria do Acesso e da Qualidade da Atenção Básica (AMAQ). Brasília; 2012b. (Série B. Textos básicos de saúde) 
Brasil. Ministério da Saúde. Secretaria de Atenção à Saúde. Departamento de Atenção Básica. Saúde Bucal. Brasília; 2008. (Série A. Normas e Manuais Técnicos; Cadernos de Atenção Básica; 17)

Brasil. Ministério da Saúde. Secretaria de Atenção à Saúde. Departamento de Atenção Básica. Política Nacional de Atenção Básica. Brasília; 2012c. (Série E. Legislação em Saúde)

Brasil. Ministério da Saúde. Secretaria de Atenção à Saúde. Departamento de Atenção Básica. Programa Nacional de Melhoria do Acesso e da Qualidade da Atenção Básica (PMAQ): manual instrutivo. Brasília; 2012d. (Série A. Normas e manuais técnicos)

Brasil. Ministério da Saúde. Secretaria de Atenção à Saúde. Departamento de Atenção Básica. Documento Síntese para Avaliação Externa do Programa acional de Melhoria do Acesso e da Qualidade da Atenção Básica (PMAQ). Brasília; 2012e.

Brasil. Ministério da Saúde/Ministério do Planejamento, Orçamento e Gestão. Fundação estatal: metas, gestão profissional e direitos preservados. Brasília; 2007.

Fontenelle LF. Mudanças recentes na política nacional da atenção básica: uma análise crítica. Rev Bras Med Farm. 2012 jan.-mar;7(22):5-9.

Miranda AS. Proposição de escopo para a avaliação da gestão no Sistema Único de Saúde. Brasília: Ministério da Saúde; 2005. Relatório final de consultoria prestada ao Ministério da Saúde.

Munkeviz MSG, Pelicione MSF. Saúde bucal na estratégia saúde da família no município de São Paulo: perspectiva do usuário. Rev Bras Cresc Desenvolvimento Hum. 2010;20(3):787-97.

Narvai PC, Frazão P. O SUS e a política nacional de saúde bucal. In: Pereira AC, organizador. Tratado de saúde coletiva em odontologia. Nova Odessa: Napoleão; 2009.

Narvai PC, Frazão P. Saúde bucal no sistema único de saúde: 20 anos de luta por uma política pública. Saúde em Debate. 2009 jan-dez;33(81):64-71. 
Paim JS. Avaliação em saúde: uma prática em construção no Brasil. In: Hartz ZMA, Vieira da Silva LM, organizadores. Avaliação em saúde: dos modelos teóricos à prática na avaliação de programas e sistemas de saúde. Rio de Janeiro: Salvador: Editora Fiocruz: EDUFBA; 2005. p. 9-10.

Paulus Jr A, Cardoni Jr L. Políticas públicas de saúde no Brasil. Rev Espaço Saúde. 2006 dez;8(1):13-9.

Pena PM, Malik NA. Gestão estratégia em saúde. In: Vecina Neto G, Malik AM, organizadores. Gestão em saúde. Rio de Janeiro: Guanabara Koogan; 2011.

Pereira AC, organizador. Odontologia em saúde coletiva: planejando ações e promovendo saúde. Porto Alegre: Artmed; 2003.

Pereira RL, Jeziorski LL, Facchini LA. Programa nacional de melhoria do acesso e da qualidade da atenção básica - PMAQ. In: 21ํㅡㄹ Congresso de Iniciação Científica; 4aㅡ/Amostra Científica; 20-23 nov. 2013; Pelotas (RS) [citado 28 dez. 2013]. Disponível em < http://www2.ufpel.edu.br/75nd/2012/anais/pdf/CS/CS_00975.pdf> .

Pinto HÁ. Informe técnico institucional - O programa nacional de melhoria do acesso e da qualidade e o processo de trabalho das equipes da atenção básica. Tampus Actas Saúde Coletiva [Internet]. 2012 [citado 24 ago. 2012];6(2).

Disponível em http://www.prefeitura.sp.gov.br/cidade/secretarias/saude/atencao_basica/esf/index.p $\mathrm{hp} ? \mathrm{p}=17783$ \#avaliacao $>$. Portal da prefeitura da cidade de são Paulo. Estratégia Saúde da Família-ESF

Pinto HÁ, Sousa A, Florêncio A. O Programa Nacional de Melhoria do Acesso e da Qualidade da Atenção Básica: reflexões sobre o seu desenho e processo de implantação [citado 30 set. 2013]. DOI: 10.3395/reciis.v6i2.Sup1.624pt. RECIIS, Brasil, 6, aug. 2012. Disponível em:

http://75nd.reciis.cict.fiocruz.br/75ndex.php/reciis/article/view/624/1096.

Pinto NRS, Tanaka OY, Spedo SM. Política de saúde e gestão no processo de (re)construção do SUS em município de grande porte: um estudo de caso de São Paulo, Brasil. Cad Saúde Pública [Internet]. 2009 abr [citado 27 ago. 2012]; 25(4):927-38. Disponível em: http://www.scielo.br/pdf/csp/v25n4/24.pdf. 
Pucca Jr. GA. A política nacional de saúde bucal como demanda social. Ciênc Saúde Coletiva [Internet]. 2006 Mar [citado 02 jan 2014];11(1):243-6. Disponível em: <http://www.scielo.br/scielo.php?script=sci_arttext\&pid=S1413$81232006000100033 \& \operatorname{lng}=$ pt.

Reis AF, Oliveira PTR, Sellera PE. Sistema de Avaliação e qualificação do sistema único de saúde (SUS). RECIIS - Rev Eletr Comun Inf Inov Saúde [Internet]. 2012 ago [citado 02 jan. 2013];6(2). Disponível em:

http://www.reciis.icict.fiocruz.br/index.php/reciis/article/viewArticle/622/1089.

Savassi LCM. Qualidade em serviços públicos: os desafios da atenção primária. Rev Bras Med Fam Comunidade. 2012 abr-jun;7(23): 69-74.

Tanaka OY, Melo C. Avaliação de serviços e programas de saúde para a tomada de decisão. In: Rocha AM, Cesar CLM, editores. Saúde pública: bases conceituais. São Paulo: Atheneu; 2008. p. 119-31.

Tanaka OY, Tamaki EM. O papel da avaliação para a tomada de decisão na gestão de serviços de saúde. Ciênc Saúde Coletiva [Internet]. 2012 apr [citado 31 dez. 2013];17(4):821-8. Disponível em: http://www.scielo.br/scielo.php?script=sci_arttext\&pid=S1413$81232012000400002 \&$ Ing $=$ en.

Tannus SAC, Silva LH, Kunitake CS, Kamehama S. PMAQ no município de São Paulo - MSP. In: Anais do $12^{\circ}$ Congresso Brasileiro de Medicina de Família e Comunidade; 20 maio 02 jun 2013; Belém (PA) [citado 28 dez. 2013]. Disponível em: < http://www.cmfc.org.br/index.php/brasileiro/article/view/1271>.

Verdi MIM, Da Ros MA, Cutolo LRA. Saúde e sociedade. Florianópolis: Universidade Aberta do SUS; 2012 [citado 20 dez. 2013]. Disponível em: < https://unasus2.moodle.ufsc.br/pluginfile.php/6110/mod_resource/content/1/Cont_Im presso_0504/Modulo2_Unid1_0504.pdf>. 